\title{
Bioprocess Optimization of Nutritional Parameters for Enhanced Anti-leukemic L-Asparaginase Production by Aspergillus candidus UCCM 00117: A Sequential Statistical Approach
}

\author{
Maurice Ekpenyong ${ }^{1,2}$ ([) $\cdot$ Atim Asitok ${ }^{1}$ (1) $\cdot$ Richard Antigha $^{3}$ (1) $\cdot$ Nkpa Ogarekpe $^{3}$ (1) $\cdot$ Ubong Ekong $^{2} \cdot$ \\ Marcus Asuquo ${ }^{4} \cdot$ Joseph Essien ${ }^{5,6}$ (1) $\cdot$ Sylvester Antai ${ }^{1}[\mathbb{C}$
}

Accepted: 22 February 2021 / Published online: 9 March 2021

(c) The Author(s), under exclusive licence to Springer Nature B.V. 2021

\begin{abstract}
Sequential optimization of bioprocess nutritional conditions for production of glutaminase-near-free L-asparaginase by Aspergillus candidus UCCM 00117 was conducted under shake flask laboratory conditions. Catalytic and anti-cancer activities of the poly-peptide were evaluated using standard in vitro biochemical methods. Medium nutrients were selected by one-factor-at-a-time (OFAT) approach while Plackett-Burman design (PBD) screened potential factors for optimization. Path of steepest ascent (PSA) and response surface methodology (RSM) of a Min-Run-Res V fractional factorial of a central composite rotatable design (CCRD) were employed to optimize factor levels towards improved enzyme activity. A multiobjective approach using desirability function generated through predictor importance and weighted coefficient methodology was adopted for optimization. The approach set optimum bioprocess conditions as $49.55 \mathrm{~g} / \mathrm{L}$ molasses, $64.98 \%$ corn steep liquor, $44.23 \mathrm{~g} / \mathrm{L}$ asparagine, $1.73 \mathrm{~g} / \mathrm{L}$ potassium, $0.055 \mathrm{~g} / \mathrm{L}$ manganese and $0.043 \mathrm{~g} / \mathrm{L}$ chromium (III) ions, at a composite desirability of 0.943 and an L-asparaginase activity of 5216.95U. The Sephadex-200 partially-purified polypeptide had a specific activity of $476.84 \mathrm{U} / \mathrm{mg}$; $0.087 \mathrm{U}$ glutaminase activity, $36.46 \%$ yield and 20 -fold protein purification. Anti-cancer activity potentials of the catalytic poly-peptide were dose-dependent with $\mathrm{IC}_{50}(\mu \mathrm{g} / \mathrm{mL}): 4.063$ (HL-60), 13.75 (HCT-116), 15.83 (HeLa), 11.68 (MCF-7), 7.61 (HepG-2). The therapeutic enzyme exhibited 15-fold more cytotoxicity to myeloid leukemia cell line than to normal (HEK $238 \mathrm{~T}$ ) cell. Optimum temperature and $\mathrm{pH}$ for activity were within physiological range. However, significant interactions between exposure time and levels of each of temperature and $\mathrm{pH}$ made interpretations of residual enzyme activities difficult. The manganese-dependent L-asparaginase from Aspergillu s candidus UCCM 00117 is recommended for further anticancer drug investigations.
\end{abstract}

Keywords Sequential optimization $\cdot$ Aspergillus candidus $\cdot$ L-Asparaginase activity $\cdot$ Renewable substrates $\cdot$ Anti-cancer activity $\cdot$ Selectivity index

Maurice Ekpenyong

maurygg2002@yahoo.com;

mauriceekpenyong2002@unical.edu.ng

1 Environmental Microbiology and Biotechnology Unit, Department of Microbiology, University of Calabar, Calabar, Nigeria

2 Department of Pharmaceutical Microbiology and Biotechnology, Faculty of Pharmacy, University of Calabar, Calabar, Nigeria
3 Department of Civil Engineering, Cross River University of Technology, Calabar, Cross River State, Nigeria

4 Department of Hematology, University of Calabar Teaching Hospital, Calabar, Nigeria

5 Department of Microbiology, Faculty of Science, University of Uyo, Uyo, Nigeria

6 International Centre for Energy and Environmental Sustainability Research (ICEESR), University of Uyo, Uyo, Nigeria 


\section{Introduction}

Cancers are among the topmost causes of global death and arise from uncontrolled proliferation of certain cells, tissues and organs including breast, lung, blood, liver, pancreas, stomach, colon and cervix, after exposure to certain environmental, nutritional or habitual agents (Sultana et al. 2019; Ervina et al. 2020). Certain types of cancers can also develop genetically and are heritable within genetically-related populations (Sultana et al. 2019). Cancerous cells characteristically have a requirement for asparagine having lost their ability to express the gene that encodes asparagine synthetase (Sarquis et al. 2004). In human carcinomas therefore, the primary target of anti-cancer compounds is the central sensor for nutrient and energy availability which regulates cell cycle, growth and proliferation (Luengo et al. 2017; Zhang et al. 2018). Cancer treatments have largely proceeded through surgery, radiotherapy, immunotherapy and chemotherapy employing diverse agents including inorganic (Jaros et al. 2019; Chen et al. 2020) and organic compounds or a combination of both (Bokas et al. 2020). Peptide molecules from different biological sources including plants (de Oliveira et al. 2015; Eswaraiah et al. 2020), animals (Elrayess et al. 2020) and microorganisms (Sereena and Sebastian 2020; Harish et al. 2020) have demonstrated precision in target identification and activity, and have therefore received tremendous attention as key components of anti-cancer chemotherapy in recent years.

L-asparaginases (EC 3.5.1.1) are amidohydrolases which primarily catalyze the hydrolytic cleavage of L-asparagine into L-aspartic acid and ammonia oftentimes with secondary catalytic cleavage of L-glutamine to L-glutamic acid and ammonia using glutaminase activity (Avramis 2012; Cachumba et al. 2016). The enzyme is frequently included in modern treatment regime for lymphoblastic leukemia and other lymphomas, and in acrylamide reduction protocol in the food industry (Kukurova et al. 2009; Pieters et al. 2011; Shakambari et al. 2019). L-asparaginase is frequently sourced from plants (Oza et al. 2010; Mohamed et al. 2015) and microorganisms (Sahu et al. 2007; Hassan et al. 2018). Foremost among microorganisms that produce L-asparaginases include species of Escherichia and Erwinia however; other bacteria including Bacillus velezensis (Mostafa et al. 2019), Enterobacter cloacae (Husain et al. 2016), Streptomyces rochei (El-Naggar and El-Shweihy 2020) and Geobacillus thermodenitrificans (Nadeem et al. 2019) have also been reported. Species of the genera Aspergillus, Penicillium, Fusarium (Sarquis et al. 2004) and Trichosporon (Ashok et al. 2019) dominate literature as fungal L-asparaginase producers. Aspergillus species most reported include
Aspergillus niger (Vala et al. 2018), Aspergillus terreus and Aspergillus tamari (Baskar and Sahadevan 2012; Sarquis et al. 2004).

Applications of bacterial and fungal L-asparaginases, especially from species of Bacillus (Alrumman et al. 2019) and Aspergillus (Prabavathy and Phoebe 2020), in anti-cancer research have been documented. However, the difficulty in obtaining sufficient plant L-asparaginases to meet its high demand and the allergic reactions that attend microbial L-asparaginases during clinical applications owing to secondary glutaminase co-activity are significant drawbacks in anti-cancer chemotherapy (Cecconello et al. 2020). Remedial attempts at toxicity reduction during chemotherapy have included the use of pegylated forms of the product (Appel et al. 2008) as well as sourcing for producing strains with low glutaminase activity (Mahajan et al. 2012). Currently, there is an upsurge in reports on glutaminase free L-asparaginase (El-Naggar et al. 2018) which presupposes that anti-cancer activity of L-asparaginases may not require the associated glutaminase activity (Chan et al. 2014). However, complete elimination of glutaminase activity from L-asparaginase may render the medication therapeutically ineffective (Mahajan et al. 2012). A workable remedy may well be the production of L-asparaginases with low glutaminase activity and optimizing fermentation conditions that enhance their production.

Microbial fermentations have been at the forefront of production of L-asparaginases by solid-state and submerged methods (Shakambari et al. 2019). However, yields of the product have been low and with poor production economics (Farag et al. 2015). Sourcing for high-yielding strains, improving them through genetic and metabolic manipulations; optimization of their bioprocess conditions of media, operations and downstream processing; remain reliable approaches towards yield improvement (Baskar and Sahadevan 2012; Yingling and Zhengfang 2013). Nutritional conditions for microbial fermentations have been reported to account for $30-40 \%$ of production economics of bioprocesses; sources of carbon and nitrogen being the most critical. Selection of significant nutrients for inclusion in microbial fermentation media and optimizing their levels are subjects that are vigorously pursued by industries (Shakambari et al. 2019). A sequence of reported techniques in that regard include one-factor-at-a-time (OFAT) approach that does the primary selection (Long et al. 2018) followed by a two-level factorial design like Plackett-Burman design (PBD) that establishes significance of selected factors (Mechmeche et al. 2019; Gururaj et al. 2020). A third procedure in the optimization process is path of steepest ascent (PSA) which moves significant coefficients from the first-order model of PBD close to their optimum with subsequent resetting of center points for response surface methodology (RSM)(Huang 2019). The RSM is a mathematical 
approximation method that employs special experimental design methods in sequential fashion to vary and combine levels for significant interaction effects of variables to bring about an improved condition of target response (Kowalski et al. 2005).

The present study reports the exploration of the sequence of optimization experiments conducted to enhance the fermentative production of a glutaminase near-free poly-peptide with L-asparaginase activity by a new addition to Aspergillus species in the quest for low-toxicity L-asparaginases. We are not aware of a prior report on L-asparaginase production by a strain of Aspergillus candidus. A description of the spectrum of anti-cancer activity of the therapeutic catalytic poly-peptide and its prospects for safety and stability are also reported.

\section{Materials and Methods}

\section{Microorganism}

The producing mold, Aspergillus candidus UCCM 00117 , earlier isolated by Asitok and Ekpenyong (2019) and sharing 100\% sequence homology with Aspergillus candidus JN-YG-3-2 (MG554228.1), was retrieved from the University of Calabar Collection of Microorganisms, UCCM (www.wfcc.info/ccinfo/collection/by_id/652.). The mold was reactivated in glucose-peptone broth for $72 \mathrm{~h}$ at room temperature $\left(28 \pm 2{ }^{\circ} \mathrm{C}\right)$. Next, the culture was diluted 1000 -fold and then plated on Czapek-Dox agar for $72 \mathrm{~h}$ at room temperature. Viability and L-asparaginase-producing potential were checked by transferring one agar plug $(6 \mathrm{~mm})$ of culture from Czapek-Dox agar onto freshly prepared L-asparagine agar medium composed $(\mathrm{g} / \mathrm{L})$ of $\mathrm{Na}_{2} \mathrm{HPO}_{4} 6$; $\mathrm{KH}_{2} \mathrm{PO}_{4} 3 ; \mathrm{MgSO}_{4} \cdot 7 \mathrm{H}_{2} \mathrm{O} 0.2 ; \mathrm{FeSO}_{4} \cdot 7 \mathrm{H}_{2} \mathrm{O} 0.05, \mathrm{NaCl} 0.5$; $\mathrm{CaCl}_{2} 0.5 ; \mathrm{KCl} 0.5,1 \%$ asparagine and supplemented with $0.25 \%$ phenol red. Development of pink coloration between 36 and $60 \mathrm{~h}$ was indicative of retained viability and activity for L-asparagine hydrolysis. The reactivated culture was transferred onto potato dextrose agar (PDA) on Petri dish and maintained in a refrigerator until required for further studies.

\section{One-Factor-at-a-Time (OFAT) Optimization of Variables for Maximum L-Asparaginase Activity}

\section{Carbon Source}

The preferred extraneous carbon source to drive maximum L-asparaginase activity by the study mold was selected by the traditional one-factor-at-a-time (OFAT) approach. The method involved varying the source of carbon and holding every other parameter constant (Ekpenyong et al. 2017a).
Glucose (GLU), mannose (MAN) and fructose (FRU) as monosaccharides, sucrose (SUC), maltose (MAL) and lactose (LAC) as disaccharides and agro-industrial waste products including molasses (MOL), cassava processing effluent (CPE) and rice processing effluent (RPE) were the carbon substrates screened. Sugars were purchased from Sigma-Aldrich (Sigma-Aldrich Inc., St. Louis, MO, USA) while effluents were obtained from local industries in Lagos and Calabar, Nigeria and stored at $-20{ }^{\circ} \mathrm{C}$ until required.

The minimal medium for screening contained $(\mathrm{g} / \mathrm{L})$ $\mathrm{Na}_{2} \mathrm{HPO}_{4} 6 ; \mathrm{KH}_{2} \mathrm{PO}_{4} 3 ; \mathrm{MgSO}_{4} \cdot 7 \mathrm{H}_{2} \mathrm{O} 0.2 ; \mathrm{FeSO}_{4} \cdot 7 \mathrm{H}_{2} \mathrm{O}$ $0.05, \mathrm{NaCl} 0.5 ; \mathrm{CaCl}_{2}$ 0.5; KCl 0.5 (Asitok and Ekpenyong 2019) and was supplemented with $1 \mathrm{~mL}$ trace mineral solution composed $(\mathrm{g} / \mathrm{L})$ of $\mathrm{ZnSO}_{4} \cdot 7 \mathrm{H}_{2} \mathrm{O} 0.005 ; \mathrm{MnSO}_{4} \cdot 4 \mathrm{H}_{2} \mathrm{O}$ $0.005 ; \mathrm{H}_{3} \mathrm{BO}_{3} 0.005 ; \mathrm{CuSO}_{4} .5 \mathrm{H}_{2} \mathrm{O} 0.005 ; \mathrm{CoCl}_{2} \cdot 6 \mathrm{H}_{2} \mathrm{O}$ 0.005; $\mathrm{MoCl}_{5}$ 0.005, $\mathrm{BaCl}_{2} 0.005 ; \mathrm{CrCl}_{3} \cdot 6 \mathrm{H}_{2} \mathrm{O} 0.005$; $\mathrm{FeCl}_{3} 0.005$ and $\mathrm{NiCl}_{2} \cdot 6 \mathrm{H}_{2} \mathrm{O} 0.005$ (Ekpenyong et al. 2017b). The fully-constituted medium was supplemented with $1 \%(\mathrm{w} / \mathrm{v}) \mathrm{L}$-asparagine (Merck) and $\mathrm{pH}$ adjusted to 5.8 using $1 \mathrm{~N} \mathrm{HCl}$. Medium was dispensed into $250 \mathrm{~mL}$ Erlenmeyer flasks at 20\% (v/v) and carbon sources (except the effluents) incorporated at $1 \%(\mathrm{w} / \mathrm{v})$. The effluents were retrieved from the freezer and allowed to thaw under ambient laboratory conditions and subsequently boiled to facilitate removal of un-dissolved solids. Upon cooling, effluent was centrifuged at 10,000 rpm for $20 \mathrm{~min}$ and supernatant dispensed as $20 \%(\mathrm{v} / \mathrm{v})$ into $250 \mathrm{~mL}$ Erlenmeyer flasks without adjusting pH (Nitschke et al. 2004). A control flask without extraneous carbon where asparagine served as carbon source was also set up. All arrangements were made in triplicates and flasks sterilized by autoclaving at $121{ }^{\circ} \mathrm{C}$ for $15 \mathrm{~min}$.

Upon cooling, one agar plug $(6 \mathrm{~mm})$ of reactivated and equilibrated mold culture was aseptically added to each flask. Flasks were plugged with sterile cotton wool and incubated at $30{ }^{\circ} \mathrm{C}$ on a rotary shaker agitating at $150 \mathrm{rpm}$ for $72 \mathrm{~h}$. Fermentation broth was first filtered with Whatman No.1 filter paper to remove mycelia and then centrifuged at $8,000 \mathrm{rpm}$ for $15 \mathrm{~min}$. Supernatant was twice filtered with $0.45 \mu \mathrm{m}$ and $0.22 \mu \mathrm{m}$ membrane filter (Millipore, USA) and L-asparaginase activity quantified for each flask by the Nesslerization protocol of Imada et al. (1973) using Tris- $\mathrm{HCl}$ buffer at $\mathrm{pH}$ 7.2. One unit of L-asparaginase activity (U) was defined as the amount of enzyme required to liberate one micromole of ammonia by L-asparagine hydrolysis in one minute under the study conditions. A one-way analysis of variance (oneway ANOVA) in GraphPad Prism 8 software (GraphPad, San Diego, CA, USA) was used to compare performances of the carbon sources and significant mean differences were separated by Tukey HSD test using 95\% confidence interval. 


\section{Nitrogen Source}

Extraneous nitrogen sources were also screened by the OFAT approach. Nitrogen sources included ammonium chloride $\left(\mathrm{NH}_{4} \mathrm{Cl}\right)$, potassium nitrate $\left(\mathrm{KNO}_{3}\right)$, ammonium nitrate $\left(\mathrm{NH}_{4} \mathrm{NO}_{3}\right)$, bean processing effluent (BPE), corn steep liquor (CSL), peptone (PEP) and tryptone (TYP). Organic and inorganic nitrogen sources were added at $1 \%$ $(\mathrm{w} / \mathrm{v})$ to minimal medium supplemented with $1 \%(\mathrm{w} / \mathrm{v})$ L-asparagine and selected carbon substrate. Effluent substrates were prepared as described in the section for carbon screening and used as also described. A control flask without extraneous nitrogen was also prepared. Experimental set-up, sterilization, inoculation, incubation, harvest, L-asparaginase activity assay and statistical analyses were as described under carbon screening.

\section{Inoculum Size}

To select most suitable inoculum size (spore density) for the fermentation, inoculum sizes were screened by the OFAT approach by inoculating 3\% (v/v) spore suspension of different inoculum sizes ranging from $10^{3}$ to $10^{9}$ spore-forming units per milliliter ( $\mathrm{sfu} / \mathrm{mL}$ ) into minimal medium containing selected extraneous carbon and nitrogen substrates. Working spore concentrations were prepared by the spectrophotometric method as described in Ekpenyong et al. (2020a) and experimental set up, incubations, harvest, determinations of enzyme activity and statistical analyses were as described under carbon screening section.

\section{Metal Ions}

Metal ions including $\mathrm{Na}^{+}, \mathrm{K}^{+}, \mathrm{Mg}^{2+}, \mathrm{Ca}^{2+}, \mathrm{Zn}^{2+}, \mathrm{Mn}^{2+}$, $\mathrm{Ni}^{2+}, \mathrm{Cu}^{2+}, \mathrm{Co}^{2+}, \mathrm{Fe}^{2+}, \mathrm{Fe}^{3+}, \mathrm{Pb}^{2+}, \mathrm{Cr}^{3+}$ and $\mathrm{Mo}^{5+}$ were screened for their effects on L-asparaginase production. All metal salts were purchased as chlorides from Sigma-Aldrich except ferrous and magnesium salts which were purchased as hydrated sulfates from Fisher Scientific (Fisher Scientific UK Ltd, Loughborough, UK). A complete minimal medium with all salts in place as detailed under carbon screening section plus selected carbon, nitrogen and inoculum size served as control. Effect of metal ion on L-asparaginase activity was scored on the basis of L-asparaginase activity quantified in the absence of the respective metal. Higher L-asparaginase activity indicated inhibition in the presence of the metal while lower values indicated enhancement of activity. All metal ions were tested at $1 \mathrm{mM}$ concentration and experimental set-up, incubations, harvest and determinations were as described for carbon screening. Effects of metals on L-asparaginase activity were compared by one-way ANOVA and significant means separated by Dunnett test comparing metal performance to the control at $95 \%$ confidence interval.
Significant reduction in L-asparaginase activity selected respective metal for further studies.

\section{Plackett-Burman Design Screening of Selected Variables}

The Plackett-Burman design (PBD) was employed to screen a combination of 12 major and minor nutrients obtained from OFAT experiments to develop an appropriate fermentation medium for production of $\mathrm{L}$-asparaginase with maximum enzyme activity, Y. This $2^{2}$ factorial design completely ignores possible two-way factor interactions but focuses on their main effects on the response(s). The variables included in this study design were molasses (MOL), corn steep liquor (CSL), inoculum volume (INV), asparagine (ASP), $\mathrm{Na}^{+}$, $\mathrm{K}^{+}, \mathrm{Mg}^{2+}, \mathrm{Zn}^{2+}, \mathrm{Mn}^{2+}, \mathrm{Fe}^{2+}, \mathrm{Co}^{2+}$ and $\mathrm{Cr}^{3+}$. All 12 factors were tested at 2 levels; high $(+1)$ and low $(-1)$ and the design made with MINITAB 17 (MiniTab Inc, Pennsylvania, USA). The design comprised 25 experimental runs having been augmented with 5 center points to enable estimation of experimental error and test the fit of the first-order model. The factor names and their levels as employed in PBD are presented in Table DT5 of Mendeley Data (Ekpenyong et al. $2020 b)$. Only predictors with significant $(p<0.05)$ main effects selected by backward elimination were employed to build the first-order regression model for further studies. The general fitted first-order model developed by least squares method is given as Eq. 1:

$y=\beta_{0}+\sum_{i=1}^{k} \beta_{i} x_{i}+\varepsilon$

where $\mathrm{y}$ is the predicted response, $\beta_{0}$ the intercept, $\beta_{\mathrm{i}}$ the coefficients of predictors (significant) $x_{\mathrm{i}}, i=1,2, \ldots k$.

\section{Path of Steepest Ascent (PSA) Experimentation}

The path of steepest ascent (PSA) is an intermediary gradient protocol in RSM optimization experiment employed to move identified significant predictors of a process or system close to the optimum through sequential experimentation (Kowalski et al. 2005). The goal of the PSA is to identify a new operating region for significant process improvement. It finds a suitable approximation in the first-order model from the PBD which provides the coefficients of significant factors to direct operating region towards PSA subject to a given distance $\rho$, from the center point.

Since a one unit (using coded units) steepest ascent point away from the center point is desired to maximize the response, $y$, the coordinates of the significant factor levels were determined as follows: 
i. The slope of the model was calculated using the largest absolute regression coefficient, $\beta_{\mathrm{j}}$ in the model and denoted $\Delta x_{\mathrm{j}}$ as step size 1

ii. Other step sizes were then calculated using Eq. 2 as follows:

$$
\Delta x_{i}=\frac{\beta_{i}}{(\beta j / \Delta x j)} i=1,2, \ldots k \mathrm{i} \neq j
$$

iii. Then, the coded step sizes were converted to natural levels using the relationship between coded and natural levels as given in Eq. 3

$$
d X_{i}=S_{i}(\rho) i=1,2, \ldots k \mathrm{i} \neq j
$$

where $d X_{\mathrm{i}}$ is the change in natural level of predictor variables, $\Delta x i$, change in coded level of predictor variables, $S$, the slope with respect to each predictor and $\rho$ the natural level change (proportion) in the predictor, $j$, with largest absolute coefficient, $\beta$.

Therefore, using the fitted first-order model, the PSA approach moved levels of significant predictors away from the original design center along the path of steepest ascent towards maximum L-asparaginase activity. The levels of significant variables in the PSA experiment that yielded the highest L-asparaginase activity were employed as center points in RSM experiment.

\section{Response Surface Modeling of Significant Predictors for Maximum L-Asparaginase Activity}

The matrix for the response surface method (RSM) of optimization was obtained through central composite rotatable design (CCRD) using Design Expert 12 software (Stat Ease Inc., Minnesota, USA), with each numerical factor evaluated at 5 levels. Based on the number of significant factors selected by PBD, a special kind of fractional factorial design called Min-Run-Res V type factorial design was adopted for RSM. The design comprised 6 center points for lack-of-fit (LoF) test and 34 non-center points made up of 12 axial $(-1.56508$ and +1.56508$)$ and 22 factorial $(-1$ and +1$)$ points; making a total of 40 experimental runs. The predictors were coded as $x_{1}, x_{2}, x_{3}, x_{4}, x_{5}$ and $x_{6}$ corresponding to molasses, corn steep liquor, asparagine, potassium, manganese and chromium. Molasses was composed (\%) of dry solids 82.1; Sucrose 50.7; Invert sugar 0.4, Raffinose 1.1; Ash 12.0; Total nitrogen 1.7; Purity quotient of 63.1 and $\mathrm{pH}$ of 7.5. Corn steep liquor was composed, in percent weight (wt\%), of crude protein 47.2; ash (oxide) 15.3; lactic acid 24.8 , phytic acid 7.8 , fat 0.33 ; reducing sugar 2.8 , water 32 , $\mathrm{pH}$ 4.1. The actual levels of the factors were varied based on the steepest ascent steps earlier developed in the PSA section as follows: $X_{1}=(44.61) / 4.935, X_{2}=(67.97) / 2.995$, $\mathrm{X}_{3}=(40.05) / 4.175, \mathrm{X}_{4}=(1.88) / 0.146, \mathrm{X}_{5}=(50) / 5.000$, $\mathrm{X}_{6}=(47.42) / 4.57$. Details are as presented in Table DT9 of the Mendeley Dataset (Ekpenyong et al. 2020b).

The requirement to report specific activity of the enzyme and the yield coefficient of the bioprocess made the inclusion of biomass concentration $(\mathrm{g} / \mathrm{L})$ and total protein $(\mathrm{mg})$ as additional response variables necessary, at this stage of the study. Therefore, three response variables were determined in the RSM experiments namely biomass concentration $\left(\mathrm{Y}_{1}\right)$, total protein $\left(\mathrm{Y}_{2}\right)$ and L-asparaginase activity $\left(\mathrm{Y}_{3}\right)$. Biomass concentration was determined by the conventional oven dry weight technique (Banerjee et al. 1993) while total protein and L-asparaginase activity were determined by the methods of Bradford (1976) and Imada et al. (1973) respectively. All 40 completely randomized experiments were conducted in triplicates and results reported as mean responses. Data was subjected to multiple regression analysis using least squares to build/fit models. The scalar notation of the general quadratic function for RSM is given below;

$Y=\beta_{0}+\sum_{i=1}^{k} \beta_{i} x_{i}+\sum_{i=1}^{k} \beta_{i i} x_{i}^{2}+\beta_{i j} x_{i} x_{j}+\varepsilon$

where $\mathrm{y}$ is the response, $\beta_{0}, \beta_{\mathrm{i}}, \beta_{\mathrm{ii}}$ and $\beta_{\mathrm{ij}}$ are the regression coefficients for the constant, linear $\left(x_{\mathrm{i}}\right)$, quadratic $\left(x_{\mathrm{i}}^{2}\right)$ and interaction terms $\left(x_{\mathrm{i}} x_{\mathrm{j}}\right)$ of the $k$ factors respectively and $\varepsilon$ the error term of response variable computation. Only significant $(p<0.05)$ predictors of each response was included in the final model. Adequacy of models was evaluated by examining model diagnostic plots, adjusted and predicted $r^{2}$ values, LoF $F$ and $p$-values and percent coefficient of variation $(\% \mathrm{CV})$. Significant model predictors were evaluated by $t$-test of their coefficients and model curvatures presented as contour (2-D), surface (3-D) plots.

\section{Multi-Objective Optimization of Response Variables}

Since the three responses of biomass concentration $\left(\mathrm{Y}_{1}\right)$, total protein $\left(\mathrm{Y}_{2}\right)$ and L-asparaginase $\left(\mathrm{Y}_{3}\right)$ were measured during the same batch fermentation set-up under the same conditions; mono-objective optimization of responses became impracticable. This research therefore undertook a multi-objective optimization approach of the responses using the desirability function provided by response optimizer in Design Expert. The major thrusts of the research were to maximize specific activity of L-asparaginase (U/ $\mathrm{mg}$ ); calculated as the ratio of L-asparaginase activity to the amount of total protein in the culture supernatant, as well as its yield coefficient $\left(\mathrm{Y}_{\mathrm{p} / \mathrm{x}}\right)$ calculated as ratio of L-asparaginase concentration to biomass concentration and expressed 
as $\mathrm{g} / \mathrm{g}$. To achieve this therefore, a medium formulated to maximize L-asparaginase activity while minimizing biomass concentration and total protein would be ideal. The desirability function is a mathematical protocol that recommends a set of operational conditions that meet all set goals with the best desirability (Sperb et al. 2018). The composite desirability of a multi-response function was defined as the geometric mean of the desirability of individual responses and is given by the expression;

$D=\left(d_{1} \times d_{2} \times d_{3} \times \ldots \times d_{n}\right)^{\frac{1}{n}}=\left(\prod_{i=1}^{n} d i\right)^{\frac{1}{n}}$

where $\mathrm{D}$ is the composite desirability, $n$ is the number of responses, $d_{1}, d_{2}, d_{3}$ and $d_{\mathrm{n}}$ are desirability for individual responses. The equation could be weighted to reflect the importance of the responses in the desirability measure where the weight, $w_{\mathrm{i}}$ satisfies the function $0<1<w_{\mathrm{i}}$, with $w_{1}+w_{2}+w_{3}+\ldots+w_{\mathrm{n}}=1$, as follows:

$D=\left(d_{1}^{w 1} \times d_{2}^{w 2} \times d_{3}^{w 3} \times \ldots \times d_{n}^{w n}\right)^{\frac{1}{n}}$

\section{Confirmation Experiments for RSM Multi-objective Optimization}

Triplicate experiments were set up in $1 \mathrm{~L}$ Erlenmeyer flasks containing media $(20 \% \mathrm{v} / \mathrm{v})$ formulated according to significant factor settings recommended by the multi-objective numerical optimization. The three responses were measured as earlier described and specific L-asparaginase activity and yield coefficient calculated. Results from confirmation experiments were compared with those obtained in the numerical optimization and a less than 5\% difference in L-asparaginase activities was accepted as confirmatory for optimal settings.

\section{Fractionation of L-Asparaginase by Ammonium Sulfate}

The sterile crude L-asparaginase broth was gradually brought to $40 \%$ saturation with ammonium sulfate (enzyme grade) and the precipitate removed by centrifugation at $12,000 \mathrm{rpm}$ for $10 \mathrm{~min}$. The resulting supernatant was then brought to $80 \%$ saturation with the salt and further purification conducted as described in Asitok and Ekpenyong (2019). The resulting fraction was dialyzed against $0.05 \mathrm{M}$ Tris-HCl buffer ( $\mathrm{pH} 7.2)$ at $4{ }^{\circ} \mathrm{C}$ for $24 \mathrm{~h}$ with 12 changes. Total protein (Bradford 1976), L-asparaginase and glutaminase activities (Imada et al. 1973) were determined from the concentrated dialyzed supernatant.

\section{DEAE-Cellulose Column Purification}

The dialyzed enzyme fraction obtained from the fractionation experiment was loaded into a di-ethyl-amino-ethyl (DEAE)-cellulose $10 \mathrm{~cm}$ column (Sigma-Aldrich) and further purification conducted as described by Sahu et al. (2007). Total protein and activities of L-asparaginase and glutaminase were determined from the pooled concentrated dialyzed fraction as described earlier.

\section{Gel Filtration with Sephadex G-200}

The concentrated fraction of the crude enzyme from the cellulose column purification step was applied onto Sephadex G-200 gel and further purification performed as described in Husain et al. (2016). The eluted fractions were pooled into a composite sample, dialyzed as earlier described and concentrated with $0.05 \mathrm{M}$ sucrose and protein concentration, L-asparaginase and L-glutaminase activities of the partiallypurified enzyme determined as described earlier.

\section{In-Vitro Anti-cancer Activities of Aspergillus candidus UCCM-00117 L-Asparaginase}

The in vitro anti-cancer activity of the partially-purified L-asparaginase in this study was investigated using the MTT-based cytotoxicity assay of Skehan et al. (1990). Human myeloid leukemia (HL-60), colorectal carcinoma (HCT-116), cervical epithelial carcinoma (HeLa), breast cancer (MCF-7) and hepatocellular carcinoma (HepG-2) cell lines were employed to evaluate the therapeutic potentials of the enzyme. Toxicity to normal cells was tested against non-tumor human embryonic cell line (HEK 283 T) to evaluate the selective toxicity of the enzyme. Enzyme dosages were two-fold dilutions from enzyme stock solution ranging from 1.148 to $1174.898 \mu \mathrm{g} / \mathrm{mL}$. Mycoplasma sterility tests, viability and subsequent cytotoxicity studies using the sulforhodamine B (SRB) assay were as described in Asitok and Ekpenyong (2019) and Ekpenyong et al. (2020a). Experiments were conducted in triplicates and results, expressed as $\%$ cell viability, were presented as means of triplicate determinations. Cell viability was calculated using the relationship below:

$\%$ Cellviability $=\left(\frac{A_{570 T}}{A_{570 C}}\right) \times 100$

where A570T is the absorbance at $570 \mathrm{~nm}$ of cells treated with L-asparaginase and $\mathrm{A} 570 \mathrm{C}$ is the absorbance at $570 \mathrm{~nm}$ 
of untreated (control) cells. Data was analyzed by non-linear regression using the sigmoidal four-parameter logistic (4PL) model presented as Eq. 8.

$$
y=d+\frac{a-d}{1+\left(\frac{x}{c}\right)^{b}}
$$

where $x$ is the independent variable and $y$, the dependent variable; the 4 estimated parameters include $a$; the minimum value that can be obtained (i.e. what happens at 0 dose), $d$; the maximum value that can be obtained (i.e. what happens at infinite dose), $c$; the point of inflection (i.e. the point on the sigmoidal curve half-way between $a$ and $d$ ) called $\mathrm{IC}_{50}$ or $\mathrm{EC}_{50}$ and $b$; the Hill's slope of the curve.

Selectivity index (SI) of the enzyme was calculated as a ratio of $\mathrm{IC}_{50}$ of non-tumor cell line to those of cancer cell lines and data was analyzed by two-way ANOVA.

\section{Evaluation of Temperature, $\mathrm{pH}$ and Metal lon Effects on L-Asparaginase Activity and Stability}

The temperature and $\mathrm{pH}$ effects on L-asparaginase activity earlier reported in Asitok and Ekpenyong (2019) were repeated to confirm the optimum temperature $\left(5-70{ }^{\circ} \mathrm{C}\right)$ and $\mathrm{pH}(3-12)$ for maximum activity of the enzyme. Reported values were means of triplicate determinations \pm standard deviation. One way analysis of variance (one-way ANOVA) was used to compare data and significant mean differences were separated by Tukey HSD at $p<0.05$. Furthermore, the thermal stability of the enzyme was evaluated by first exposing the enzyme in $50 \mathrm{mM}$ Tris- $\mathrm{HCl}$ buffer ( $\mathrm{pH} 7.5)$ to different temperatures including $40,50,60,70$ and $80^{\circ} \mathrm{C}$ for $0,15,30,45,60,75,90 \mathrm{~min}$. The enzyme was allowed to refold on ice for $15 \mathrm{~min}$ and then residual activity determined. Similarly, stability of the enzyme to increasing $\mathrm{pH}$ levels was evaluated by incubating enzyme in different buffers of varying $\mathrm{pH}$ values (Iboyo et al. 2017) ranging from 4.5 to 10.5 at $4{ }^{\circ} \mathrm{C}$ for $0,6,12,18,24$ and $30 \mathrm{~h}$. Residual activity of the enzyme was again determined after incubation as described for thermal stability. Data for enzyme stability studies were analyzed by two-way ANOVA in GraphPad Prism 8 to compare significant means and identify possible interactions at $p<0.05$.

Inhibition or enhancement of enzyme activity by metal ions was investigated by incubating the enzyme reaction mixture with $1 \mathrm{mM}$ concentration of each metal ion $\mathrm{Na}^{+}$, $\mathrm{K}^{+}, \mathrm{Mg}^{2+}, \mathrm{Ca}^{2+}, \mathrm{Ba}^{2+}, \mathrm{Zn}^{2+}, \mathrm{Ni}^{2+}, \mathrm{Fe}^{2+}, \mathrm{Fe}^{3+}, \mathrm{Cr}^{3+}, \mathrm{Mn}^{2+}$, $\mathrm{Co}^{2+}, \mathrm{Cu}^{2+}$ and $\left.\mathrm{Mo}^{5+}\right)$. Relative activities were calculated using assay without metal as control. One-way analysis of variance was used to compare data for significant mean differences at $p<0.05$. Range finding experiments for significant activity enhancing metal ions were conducted using $0.5,1.0,1.5,2.0,2.5$ and $3.0 \mathrm{mM}$ concentration. All experiments were conducted in triplicates and relative activities calculated and reported as mean value \pm standard deviation.

\section{Results and Discussion}

\section{One-Factor-at-a-Time (OFAT) Experiments}

Frequently in microbial fermentations, the carbon substrate that drives cellular metabolism differs from the one that enhances target metabolite synthesis (Abalos et al. 2002). Among the 9 carbon substrates screened by OFAT, only sucrose, cassava processing effluent and molasses significantly $(p<0.05)$ enhanced L-asparaginase activity above control (Fig. 1a). The Tukey's multiple comparisons test and its 95\% confidence interval plot (Fig. DF1 in Mendeley Data: Ekpenyong et al. 2020b) showed that molasses was the best $(p<0.0001)$ of all substrates tested with $\mathrm{L}$-asparaginase activity of $1281 \pm 32.71 \mathrm{U}$ against $933.0 \pm 20.02 \mathrm{U}$ in the control. Selection of molasses as most suitable carbon substrate for microbial production of value-added metabolites is not new. Asitok and Ekpenyong (2019) reported selection of sucrose, the dominant carbohydrate in molasses, as best carbon substrate for the mold. Ebeed and Aboutaleb (2014) had earlier reported the preference of black strap molasses as carbon source for L-asparaginase production by Acinetobacter radioresistence PS14. Production of L-asparaginase on agro-industrial wastes have been suggested as a sustainable approach towards improved production economics of biotechnological products.

The OFAT experiment to select appropriate extraneous nitrogen source for improved L-asparaginase activity using molasses as extraneous carbon substrate revealed that tryptone $(1387 \pm 62.18 \mathrm{U})$ and corn steep liquor $(1602 \pm 93.34 \mathrm{U})$ were the only nitrogen sources which significantly improved the activity of the enzyme (Fig. 1b). Corn steep liquor was selected with a slight edge over tryptone $(p=0.0188<0.05)$ as best enhancing nitrogen source while urea significantly $(p<0.0001)$ inhibited L-asparaginase activity, allowing only an activity of $873.8 \pm 90.87 \mathrm{U}$. Inhibition of L-asparaginase activity by urea had earlier been reported by Li et al. (2018) to proceed through sustained denaturation of thermo-stable L-asparaginase from Pyrococcus yayanosii $\mathrm{CH} 1$ expressed in Bacillus subtilis 168. Production of L-asparaginase by Aspergillus niger on corn steep liquor had earlier been reported by Zia et al. (2013). One of the remarkable things about using agro-industrial wastes as substrates for fermentation is the multiple roles they can play. In the present study it served as nitrogen source in combination with asparagine 


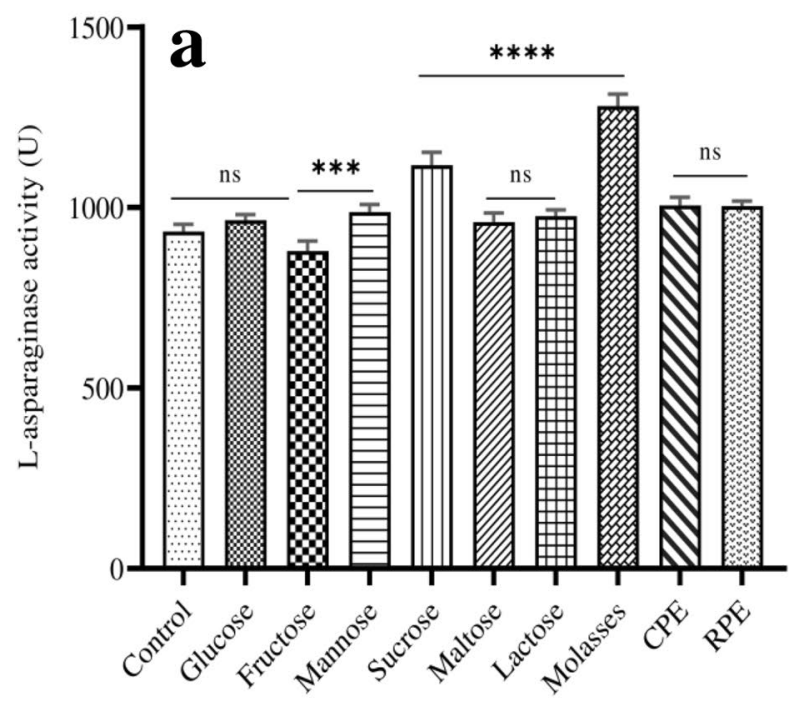

Carbon source

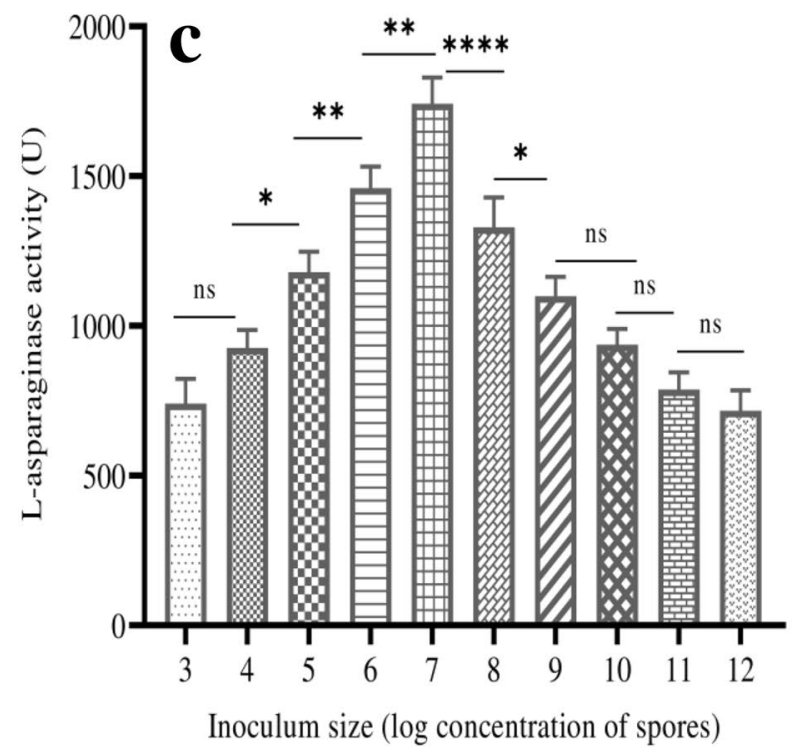

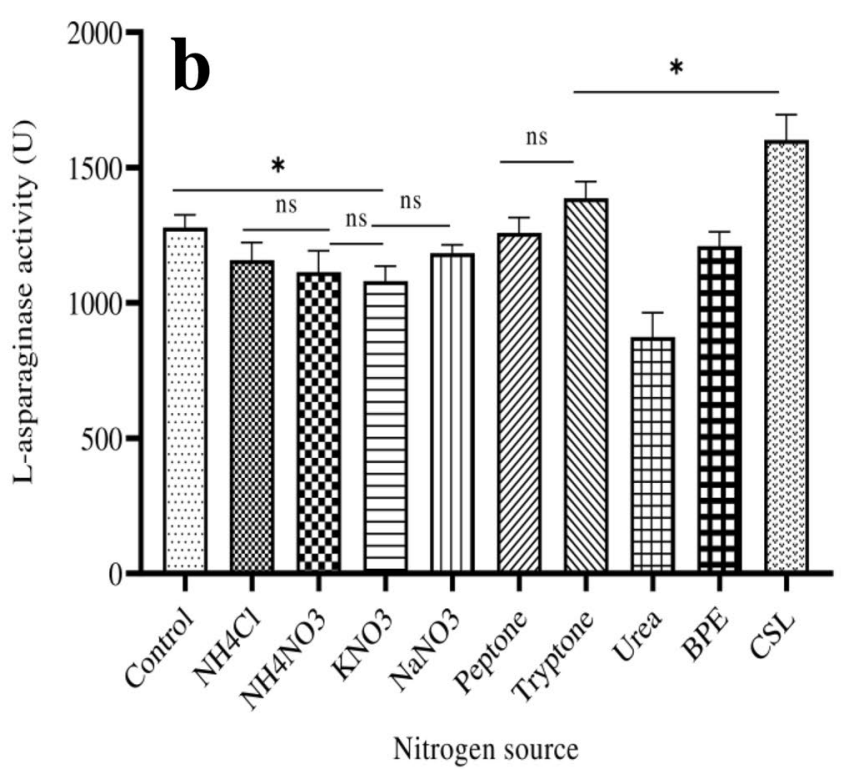

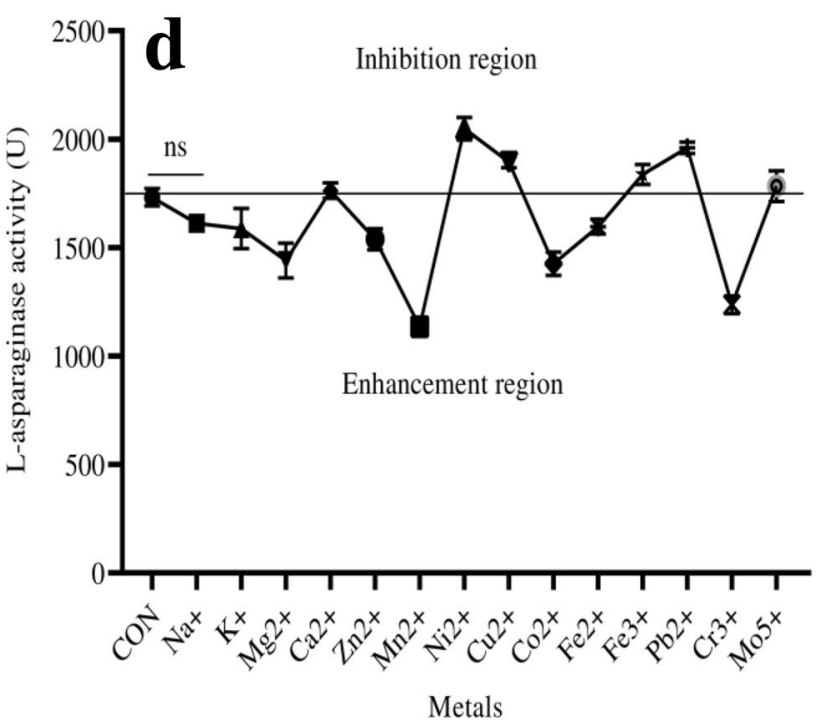

Fig. 1 One-factor-at-a-time (OFAT) plots to select most enhancing a carbon substrate b nitrogen source $\mathbf{c}$ spore density $\mathbf{d}$ metal ions for enhanced L-asparaginase production

and carbon source in combination with beet molasses and asparagine.

The results presented as Fig. 1c show that L-asparaginase activity increased with increasing spore density from $740.4 \pm 82.35 \mathrm{U}$ at $10^{3}$ spore forming units per milliliter $(\mathrm{sfu} / \mathrm{mL})$ to $1742 \pm 87.16 \mathrm{U}$ when spore density was $10^{7}$ $\mathrm{sfu} / \mathrm{mL}$. Tukey multiple comparisons test of a one-way ANOVA revealed that $\mathrm{L}$-asparaginase activity reported at $10^{7} \mathrm{sfu} / \mathrm{mL}$ was significantly higher than those at $10^{6} \mathrm{sfu} / \mathrm{mL}$ $(1460 \pm 72.01 \mathrm{U})$ below it and $10^{8} \mathrm{sfu} / \mathrm{mL}(1329 \pm 99.98 \mathrm{U})$ above it. A similar range of inoculum size was reported by
Zia et al. (2013) for L-asparaginase production by Aspergillus niger.

Finally, out of 14 metal ions screened by OFAT for their effects on L-asparaginase activity, results, presented as Fig. 1d, show that L-asparaginase activity reduced from $1732 \pm 39.76 \mathrm{U}$ in the control to $1135 \pm 44.45 \mathrm{U}$ in the absence of $\mathrm{Mn}^{2+}$ and $1237 \pm 41.00 \mathrm{U}$ in the absence of $\mathrm{Cr}^{3+}$ suggesting significant $(p<0.0001)$ requirement for these ions in the fermentation medium. However, L-asparaginase activity significantly increased to $2049 \pm 51.83 \mathrm{U}$ in the absence of $\mathrm{Ni}^{2+}$ and a little less in the absence of 
$\mathrm{Pb}^{2+}, \mathrm{Cu}^{2+}$ and $\mathrm{Fe}^{3+}$ suggesting significant inhibition of L-asparaginase production or activity in their presence. This is the first report on L-asparaginase activity enhancement by trivalent chromium. However, among all metals studied by El-Naggar et al. (2018) on their effects on Streptomyces brollosae NEAE-115 L-asparaginase, maximal enzyme activity was observed in the presence of manganese. Dunnett's multiple comparisons test showed that incorporation or non-incorporation of $\mathrm{Na}^{+}, \mathrm{K}^{+}$and $\mathrm{Mo}^{5+}$ ions did not significantly influence L-asparaginase activity. The dataset for these experiments is available at Mendeley Data (Ekpenyong et al. 2020b). The report by El-Naggar et al. (2018) also supports the inhibitory effects of nickel and trivalent iron on L-asparaginase production.
Plackett-Burman Designed Experiments

In this study, PBD was applied to screen 12 factors from the OFAT experiments and the design matrix with the experimental and predicted responses of all combinations of factors is presented in Table 1. Highest experimental and predicted L-asparaginase activities of 1948.86 and 1974.0U respectively, were obtained with the factor combination in run 22 highlighted in yellow. The full regression model is presented as Eq. 9 and incorporates all 12 predictors; significant and non-significant. Their corresponding coefficient table with $t$-test result has been published as dataset in Mendeley Data (Ekpenyong et al. 2020b).

Table 1 Design matrix of coded levels of factors in Plackett-Burman design screening for L-asparaginase production by Aspergillus candidus UCCM 00117and their experimental and predicted responses

\begin{tabular}{|c|c|c|c|c|c|c|c|c|c|c|c|c|c|c|}
\hline Run & MOL & CSL & INV & ASP & $\mathrm{Na}+$ & $\mathrm{K}+$ & $\mathrm{Mg} 2+$ & $\mathrm{Zn} 2+$ & $\mathrm{Mn} 2+$ & $\mathrm{Co} 2+$ & $\mathrm{Fe} 2+$ & $\mathrm{Cr} 3+$ & eASPNase act & pASPNase act \\
\hline 1 & -1 & 1 & 1 & -1 & -1 & -1 & -1 & 1 & -1 & 1 & -1 & 1 & 1555.31 & 1577.51 \\
\hline 2 & -1 & 1 & -1 & 1 & -1 & 1 & 1 & 1 & 1 & -1 & -1 & 1 & 1887.96 & 1919.39 \\
\hline 3 & 1 & -1 & 1 & 1 & -1 & -1 & -1 & -1 & 1 & -1 & 1 & -1 & 1784.72 & 1762.58 \\
\hline 4 & 1 & 1 & -1 & -1 & -1 & -1 & 1 & -1 & 1 & -1 & 1 & 1 & 1883.89 & 1858.46 \\
\hline 5 & -1 & 1 & 1 & -1 & 1 & 1 & -1 & -1 & -1 & -1 & 1 & -1 & 1563.58 & 1530.53 \\
\hline 6 & -1 & -1 & 1 & 1 & -1 & 1 & 1 & -1 & -1 & -1 & -1 & 1 & 1701.55 & 1693.25 \\
\hline 7 & 1 & 1 & -1 & -1 & 1 & 1 & -1 & 1 & 1 & -1 & -1 & -1 & 1836.29 & 1811.48 \\
\hline 8 & 1 & -1 & -1 & 1 & 1 & -1 & 1 & 1 & -1 & -1 & -1 & -1 & 1639.74 & 1621.16 \\
\hline 9 & 1 & 1 & 1 & -1 & -1 & 1 & 1 & -1 & 1 & 1 & -1 & -1 & 1798.46 & 1811.48 \\
\hline 10 & 0 & 0 & 0 & 0 & 0 & 0 & 0 & 0 & 0 & 0 & 0 & 0 & 1707.28 & 1711.21 \\
\hline 11 & 1 & -1 & 1 & -1 & 1 & 1 & 1 & 1 & -1 & -1 & 1 & 1 & 1694.84 & 1714.64 \\
\hline 12 & 0 & 0 & 0 & 0 & 0 & 0 & 0 & 0 & 0 & 0 & 0 & 0 & 1693.29 & 1711.21 \\
\hline 13 & 0 & 0 & 0 & 0 & 0 & 0 & 0 & 0 & 0 & 0 & 0 & 0 & 1652.21 & 1711.21 \\
\hline 14 & -1 & 1 & 1 & 1 & 1 & -1 & -1 & 1 & 1 & -1 & 1 & 1 & 1838.88 & 1837.08 \\
\hline 15 & 1 & 1 & -1 & 1 & 1 & -1 & -1 & -1 & -1 & 1 & -1 & 1 & 1887.85 & 1835.18 \\
\hline 16 & 1 & -1 & -1 & -1 & -1 & 1 & -1 & 1 & -1 & 1 & 1 & 1 & 1733.84 & 1714.64 \\
\hline 17 & -1 & -1 & 1 & -1 & 1 & -1 & 1 & 1 & 1 & 1 & -1 & -1 & 1484.75 & 1504.92 \\
\hline 18 & 1 & 1 & 1 & 1 & -1 & -1 & 1 & 1 & -1 & 1 & 1 & -1 & 1654.95 & 1705.88 \\
\hline 19 & -1 & -1 & -1 & -1 & -1 & -1 & -1 & -1 & -1 & -1 & -1 & -1 & 1344.81 & 1363.49 \\
\hline 20 & 0 & 0 & 0 & 0 & 0 & 0 & 0 & 0 & 0 & 0 & 0 & 0 & 1678.49 & 1711.21 \\
\hline 21 & -1 & -1 & -1 & -1 & 1 & -1 & 1 & -1 & 1 & 1 & 1 & 1 & 1679.33 & 1634.21 \\
\hline 22 & 1 & -1 & 1 & 1 & 1 & 1 & -1 & -1 & 1 & 1 & -1 & 1 & 1948.86 & 1974.2 \\
\hline 23 & -1 & -1 & -1 & 1 & -1 & 1 & -1 & 1 & 1 & 1 & 1 & -1 & 1729.78 & 1705.38 \\
\hline 24 & -1 & 1 & -1 & 1 & 1 & 1 & 1 & -1 & -1 & 1 & 1 & -1 & 1682.24 & 1648.67 \\
\hline 25 & 0 & 0 & 0 & 0 & 0 & 0 & 0 & 0 & 0 & 0 & 0 & 0 & 1717.25 & 1711.21 \\
\hline
\end{tabular}

$M O L$ Molasses, $C L S$ Corn steep liquor, INV inoculum volume, ASP Asparagine; $\mathrm{Na}^{+}=\mathrm{NaCl} ; \mathrm{K}^{+}=\mathrm{KCl} ; \mathrm{Mg}^{2+}=\mathrm{MgSO}_{4} \cdot 7 \mathrm{H}_{2} \mathrm{O} ; \mathrm{Zn}^{2+}=\mathrm{ZnCl}_{2}$; $\mathrm{Mn}^{2+}=\mathrm{MnCl}_{2} ; \mathrm{Co}^{2+}=\mathrm{CoCl}_{2} ; \mathrm{Fe}^{2+}=\mathrm{FeSO}_{4} \cdot 7 \mathrm{H}_{2} \mathrm{O} ; \mathrm{Cr}^{3+}=\mathrm{CrCl}_{3} \cdot 6 \mathrm{H}_{2} \mathrm{O}$. Coded values are low (-), high (+) and center points $(0)$ to facilitate determination of lack-of-fit of the model; eASPNase act = experimental L-asparaginase activity; pASPNase act = predicted L-asparaginase activity. Values of L-asparaginase activity are means of triplicate determinations 


$$
\begin{aligned}
\hat{Y}= & 1711.21+69.76 \mathrm{MOL}+42.36 \mathrm{CSL}-13.99 \mathrm{INV}+59.07 \mathrm{ASP} \\
& +9.05 \mathrm{Na}^{+}+41.16 \mathrm{~K}^{+}-5.81 \mathrm{Mg}^{2+}-10.95 \mathrm{Zn}^{2+} \\
& +70.71 \mathrm{Mn}^{2+}-1.04 \mathrm{Co}^{2+}+8.02 \mathrm{~F} e^{2+}+64.65 \mathrm{Cr}^{3+}
\end{aligned}
$$

where, $\hat{Y}=$ predicted L-asparaginase activity, MOL $=$ molasses, $\mathrm{CSL}=$ corn steep liquor, INV = inoculum volume, ASP $=$ asparagine, $\mathrm{Na}^{+}=$sodium ions, $\mathrm{K}^{+}=$potassium ions, $\mathrm{Mg}^{2+}=$ magnesium ions, $\mathrm{Zn}^{2+}=$ zinc ions, $\mathrm{Mn}^{2+}=$ manganese (II) ions, $\mathrm{Co}^{2+}=$ cobalt (II) ions, $\mathrm{Fe}^{2+}=$ Iron (II) ions and $\mathrm{Cr}^{3+}=$ chromium (III) ions. The model was significant with an $r^{2}$ of 0.9747 , adjusted $r^{2}$ of 0.9493 , predicted $r^{2}$ of 0.8785 , non-significant lack-of-fit test of $F(8,12)=1.64$, $p=0.333>0.05$. However, to achieve the primary objective of PBD viz screening, the backward elimination method was adopted to reduce the model to include only significant $(p<0.05)$ predictors as in Eq. 10 below:
Eq. 9 as important variables for L-asparaginase production while Fig. 2 b reveals their levels of importance through main effects plot. The residual plots (Fig. 2c) confirm the adequacy of the reduced model to explain the events leading to the activity of L-asparaginase observed during fermentation.

\section{Path of Steepest Ascent Experiments}

Results of the path of steepest ascent (PSA) experiments are reported in Table 3 and Fig. 3. The table summarizes the steps taken to arrive at the steepest ascent step sizes used to develop the steepest ascent experiments. The primary objective of the PSA was to identify plausible center points for the predictors suggested by the PBD first-order model for use in RSM. Table 3 assigned codes to the six predictors as $X_{1}$, $\mathrm{X}_{2}, \mathrm{X}_{3}, \mathrm{X}_{4}, \mathrm{X}_{5}$ and $\mathrm{X}_{6}$ to correspond to molasses, corn steep

$\hat{Y}=1711.21+69.76 M O L+42.36 C S L+59.07 A S P+41.16 K^{+}+70.71 M^{2+}+64.65 C r^{3+}$

The reduced model was also significant $(p<0.0001)$ at $F=59.73, r^{2}$ of 0.9522 , adjusted $r^{2}$ of 0.9362 , predicted $r^{2}$ of 0.9037 , a non-significant lack-of-fit test of $F(14,18)=2.02$, $p=0.260>0.05$. The ANOVA table for the modified model is presented as Table 2 and shows that $\mathrm{Mn}^{2+}$ and molasses made the most contributions towards enhanced L-asparaginase activity as indicated by their large $F$-values of 85.22 and 82.95 respectively. A careful examination of the predicted $r^{2}$ values reveal that the reduced model gives better prediction of L-asparaginase activity (pred. $r^{2}=90.37 \%$ ) than the full model (pred. $r^{2}=87.85 \%$ ). The diagnostic plots for the second model are given as Fig. 2. The Pareto chart (Fig. 2a) confirms the selection of the six predictors in liquor, asparagine, $\mathrm{K}^{+}, \mathrm{Mn}^{2+}$ and $\mathrm{Cr}^{3+}$ respectively. In consideration of the predictor coefficients in Eq. 9, the predictors were varied by factors of $4.935 \mathrm{~g} / \mathrm{L}, 2.995 \%, 4.175 \mathrm{~g} / \mathrm{L}$, $0.146 \mathrm{~g} / \mathrm{L}, 5 \mathrm{mg} / \mathrm{L}$ and $4.57 \mathrm{mg} / \mathrm{L}$ respectively. With these step changes, experiment 7 yielded the highest L-asparaginase activity of $3272 \pm 42.64 \mathrm{U}$ beyond which the activity took a descent (Fig. 3). The path of steepest ascent clearly identified the values of predictors which should form the center points in $\mathrm{RSM}$ as $\left(\mathrm{X}_{1}, \mathrm{X}_{2}, \mathrm{X}_{3}, \mathrm{X}_{4}, \mathrm{X}_{5}, \mathrm{X}_{6}\right)=(44.61$, $67.97,40.05,1.876,50,47.42)=(0,0,0,0,0,0)$.
Table 2 Analysis of variance of significant predictors of the modified first-order model for L-asparaginase activity from Plackett-Burman design (PBD) screening

\begin{tabular}{llllll}
\hline Source & $\begin{array}{l}\text { Degrees of } \\
\text { Freedom }\end{array}$ & $\begin{array}{l}\text { Adjusted sum of } \\
\text { Squares }\end{array}$ & $\begin{array}{l}\text { Adjusted mean } \\
\text { square }\end{array}$ & $F$-value & $p$-value \\
\hline Regression & 6 & 420,483 & 70,080 & 59.73 & 0.000 \\
Molasses & 1 & 97,336 & 97,336 & 82.95 & 0.000 \\
Corn steep liquor & 1 & 35,887 & 35,887 & 30.58 & 0.000 \\
Asparagine & 1 & 69,789 & 69,789 & 59.48 & 0.000 \\
Potassium ions & 1 & 33,880 & 33,880 & 28.87 & 0.000 \\
Manganese ions & 1 & 99,999 & 99,999 & 85.22 & 0.000 \\
Chromium (III) ions & 1 & 83,891 & 83,891 & 71.24 & 0.000 \\
Error & 18 & 21,121 & 1173 & & \\
Lack-of-Fit & 14 & 18,509 & 1322 & 2.02 & 0.26 \\
Pure Error & 4 & 2612 & 653 & & \\
Total & 24 & 441,603 & & & \\
\hline
\end{tabular}

$\mathrm{S}=34.25 ; r^{2}=95.22 \%$; Adjusted $r^{2}=93.62 \%$; Predicted $r^{2}=90.37 \%$ 

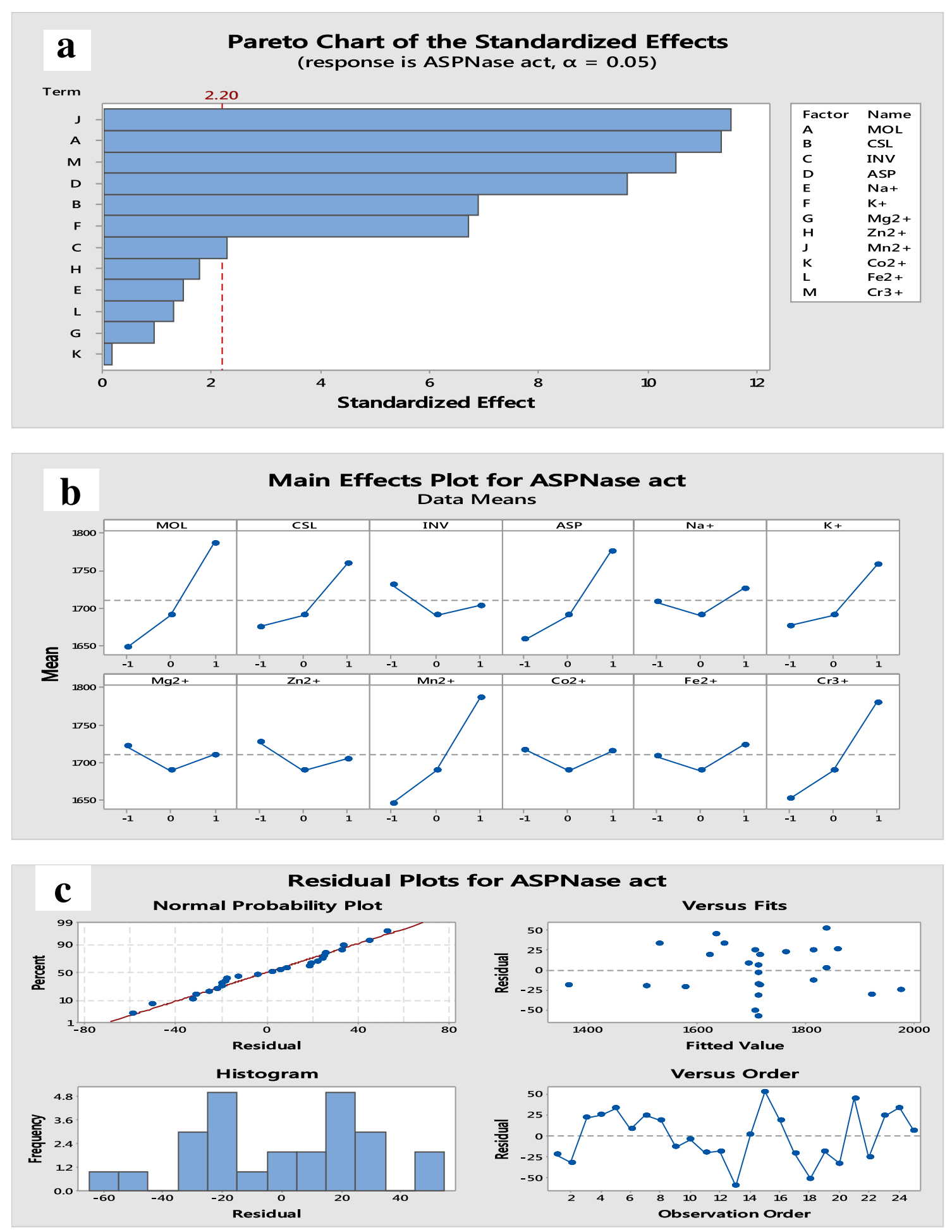

Fig. 2 Plackett-Burman design a Pareto plot showing significant factor selection. b Main effects plot of each factor contribution. $\mathbf{c}$ Diagnostic plots to test adequacy of the first-order regression model for significant predictors towards L-asparaginase production 
Table 3 Path of steepest ascent (PSA) optimization of significant predictors for enhanced L-asparaginase activity during fermentation by Aspergillus candidus UCCM 00117

\begin{tabular}{|c|c|c|c|c|c|c|c|c|c|c|c|c|c|}
\hline & $x_{1}$ & $x_{2}$ & $x_{3}$ & $x_{4}$ & $x_{5}$ & $x_{6}$ & $\mathrm{MOL}^{a}$ & $\mathrm{CSL}^{b}$ & $\mathrm{ASP}^{c}$ & $\mathrm{~K}^{+d}$ & $\mathrm{Mn}^{2+e}$ & $\mathrm{Cr}^{3+f}$ & $\begin{array}{l}\text { Mean } \\
\text { L-ASPNase } \\
\text { act } \pm \text { SE }^{l}\end{array}$ \\
\hline Base point (origin) ${ }^{g}$ & 0 & 0 & 0 & 0 & 0 & 0 & 15 & 50 & 15 & 1 & 20 & 20 & \\
\hline Original step unit ${ }^{h}$ & & & & & & & 5 & 5 & 5 & 0.25 & 5 & 5 & \\
\hline Coefficients, $\beta^{i}$ & 69.76 & 42.36 & 59.07 & 41.16 & 70.71 & 64.65 & $\mathrm{X}_{1}$ & $\mathrm{X}_{2}$ & $\mathrm{X}_{3}$ & $\mathrm{X}_{4}$ & $\mathrm{X}_{5}$ & $\mathrm{X}_{6}$ & \\
\hline $\begin{array}{l}\text { Steepest ascent step } \\
\text { distance, } \Delta\end{array}$ & $0.987^{j}$ & $0.599^{j}$ & $0.835^{j}$ & $0.582^{j}$ & $1^{j}$ & $0.914^{j}$ & $4.935^{k}$ & $2.995^{k}$ & $4.175^{k}$ & $0.146^{k}$ & $5^{k}$ & $4.57^{k}$ & \\
\hline Exp.1 (Origin) & 0 & 0 & 0 & 0 & 0 & 0 & 15 & 50 & 15 & 1 & 20 & 20 & $1683 \pm 34.46$ \\
\hline Exp. $2\left(\right.$ Origin $\left.+\Delta^{m}\right)$ & 0.987 & 0.599 & 0.835 & 0.582 & 1 & 0.914 & 19.935 & 52.995 & 19.175 & 1.146 & 25 & 24.57 & $1987 \pm 55.15$ \\
\hline Exp. $3($ Origin $+2 \Delta)$ & 1.974 & 1.198 & 1.67 & 1.164 & 2 & 1.828 & 24.87 & 55.99 & 23.35 & 1.292 & 30 & 29.14 & $2262 \pm 41.14$ \\
\hline Exp. $4($ Origin $+3 \Delta)$ & 2.961 & 1.797 & 2.505 & 1.746 & 3 & 2.742 & 29.805 & 58.985 & 27.525 & 1.438 & 35 & 33.71 & $2495 \pm 51.16$ \\
\hline Exp. $5($ Origin $+4 \Delta)$ & 3.948 & 2.396 & 3.34 & 2.328 & 4 & 3.656 & 34.74 & 61.98 & 31.7 & 1.584 & 40 & 38.28 & $2659 \pm 36.98$ \\
\hline Exp. $6($ Origin $+5 \Delta)$ & 4.935 & 2.995 & 4.175 & 2.91 & 5 & 4.57 & 39.675 & 64.975 & 35.875 & 1.73 & 45 & 42.85 & $2919 \pm 40.50$ \\
\hline Exp. $7($ Origin $+6 \Delta)$ & 5.922 & 3.594 & 5.01 & 3.492 & 6 & 5.484 & 44.61 & 67.97 & 40.05 & 1.876 & 50 & 47.42 & $3272 \pm 42.64$ \\
\hline Exp. $8($ Origin $+7 \Delta)$ & 6.909 & 4.193 & 5.845 & 4.074 & 7 & 6.398 & 49.545 & 70.965 & 44.225 & 2.022 & 55 & 51.99 & $2769 \pm 55.10$ \\
\hline Exp. $9($ Origin $+8 \Delta)$ & 7.896 & 4.792 & 6.68 & 4.656 & 8 & 7.312 & 54.48 & 73.96 & 48.4 & 2.168 & 60 & 56.56 & $2362 \pm 47.69$ \\
\hline
\end{tabular}

Exp. Experiment, $L$-ASPNase act $\mathrm{L}$-asparaginase activity, $x_{1}-x_{6}$ model codes for predictors, $\mathrm{X}_{1}-\mathrm{X}_{6}$ Actual predictor codes

N/B: ${ }^{\mathrm{a}}$ Molasses; ${ }^{\mathrm{b}}$ Corn steep liquor; ${ }^{\mathrm{c}}$ Asparagine; ${ }^{\mathrm{d}}$ Potassium ions; ${ }^{\mathrm{e}}$ Manganese (II) ions; ${ }^{\mathrm{f}}$ Chromium (III) ions; ${ }^{\mathrm{g}}$ Predictor levels at center points in PBD; ${ }^{\text {h}}$ Original step units of predictors in the PBD matrix; ${ }^{\mathrm{i} C o e f f i c i e n t s ~ o f ~ s i g n i f i c a n t ~ p r e d i c t o r s ~ i n ~ t h e ~ f i r s t-o r d e r ~ m o d e l ~ f r o m ~ P B D ; ~}{ }^{j} \mathrm{Steepest}$ ascent coded unit step distance; ${ }^{k}$ coded ascent natural unit step distance; ${ }^{1}$ Standard error of means of triplicate determinations of L-asparaginase activity; ${ }^{\mathrm{m}}$ steepest ascent step change

Fig. 3 Path of steepest ascent (PSA) experiments plot to maximize L-asparaginase activity

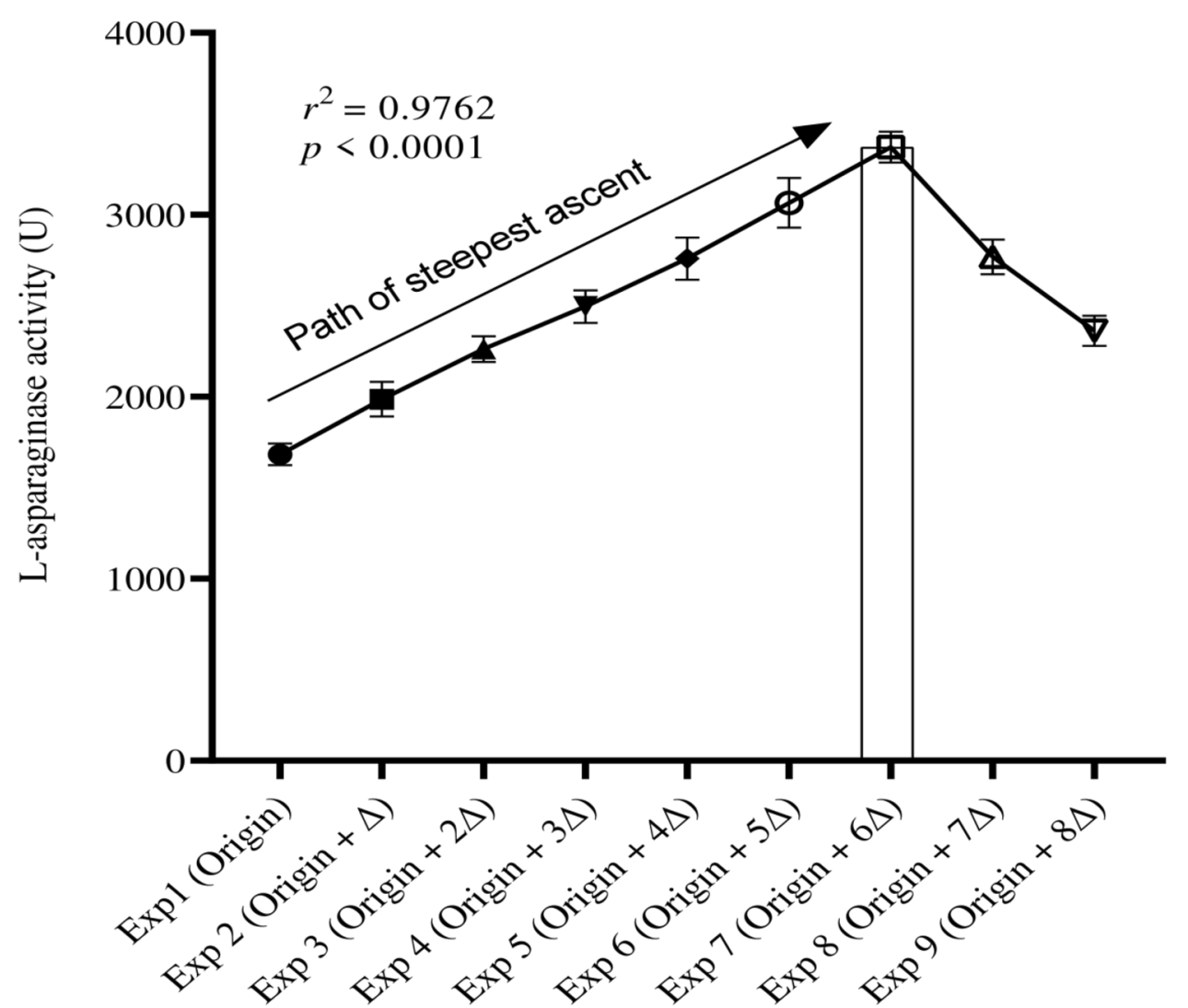

Path of steepest ascent experiments 
Table 4 Design codes, experimental and predicted values of responses of a surface methodology

\begin{tabular}{|c|c|c|c|c|c|c|c|c|c|c|c|c|}
\hline Run & $x_{1}$ & $x_{2}$ & $x_{3}$ & $x_{4}$ & $x_{5}$ & $x_{6}$ & $\mathrm{eY}_{1}$ & $\mathrm{pY}_{1}$ & $\mathrm{eY}_{2}$ & $\mathrm{pY}_{2}$ & $\mathrm{eY}_{3}$ & $\mathrm{pY}_{3}$ \\
\hline 1 & 1 & -1 & -1 & -1 & 1 & 1 & 355.63 & 355.47 & 224.56 & 224.52 & 4924.78 & 4927.74 \\
\hline 2 & -1.565 & 0 & 0 & 0 & 0 & 0 & 351.92 & 352.46 & 236.26 & 237.25 & 3198.57 & 3194.52 \\
\hline 3 & -1 & 1 & 1 & 1 & 1 & 1 & 350.24 & 350.13 & 227.87 & 227.82 & 3974.55 & 3978.16 \\
\hline 4 & -1 & -1 & 1 & 1 & -1 & 1 & 345.23 & 345.14 & 222.13 & 222.01 & 3327.49 & 3331.28 \\
\hline 5 & 1 & 1 & 1 & -1 & -1 & 1 & 387.91 & 387.34 & 265.39 & 265.11 & 3815.84 & 3825.71 \\
\hline 6 & 0 & 0 & 0 & 0 & 0 & 0 & 361.73 & 363.88 & 255.23 & 255.32 & 3294.84 & 3290.22 \\
\hline 7 & 1 & 1 & 1 & 1 & -1 & -1 & 358.64 & 358.11 & 227.45 & 227.17 & 3724.18 & 3727.87 \\
\hline 8 & 1 & -1 & 1 & -1 & -1 & -1 & 349.29 & 348.7 & 221.86 & 221.38 & 4235.27 & 4239.41 \\
\hline 9 & 0 & 0 & 0 & 0 & 0 & 0 & 365.34 & 363.88 & 255.2 & 255.32 & 3263.64 & 3290.22 \\
\hline 10 & -1 & -1 & -1 & 1 & -1 & -1 & 347.23 & 347.15 & 218.27 & 218.07 & 3086.24 & 3084.91 \\
\hline 11 & 1.565 & 0 & 0 & 0 & 0 & 0 & 375.22 & 376.38 & 259.22 & 259.55 & 3698.59 & 3685.13 \\
\hline 12 & 1 & 1 & 1 & -1 & -1 & -1 & 358.23 & 359.24 & 239.77 & 240.5 & 3628.46 & 3622.72 \\
\hline 13 & 0 & 0 & 0 & 0 & 0 & 0 & 363.38 & 363.88 & 256.48 & 255.32 & 3264.89 & 3290.22 \\
\hline 14 & 0 & 0 & 0 & 0 & -1.565 & 0 & 356.27 & 357.19 & 235.06 & 236.01 & 3258.37 & 3249.51 \\
\hline 15 & -1 & 1 & -1 & 1 & 1 & -1 & 338.22 & 338.12 & 223.55 & 223.42 & 3175.44 & 3173.92 \\
\hline 16 & 1 & 1 & 1 & -1 & 1 & -1 & 352.38 & 351.74 & 230.67 & 230.34 & 4235.47 & 4239.25 \\
\hline 17 & 0 & 0 & 0 & 0 & 0 & 0 & 365.37 & 363.88 & 257.54 & 255.32 & 3284.46 & 3290.22 \\
\hline 18 & 0 & 0 & 1.565 & 0 & 0 & 0 & 348.77 & 349.87 & 234.06 & 234.8 & 3958.84 & 3942 \\
\hline 19 & -1 & 1 & 1 & -1 & -1 & -1 & 348.23 & 347.72 & 220.92 & 220.26 & 3799.05 & 3800.42 \\
\hline 20 & 0 & 0 & 0 & 0 & 1.565 & 0 & 350.05 & 350.83 & 235.82 & 236.19 & 3945.74 & 3937.08 \\
\hline 21 & 0 & 0 & 0 & 0 & 0 & 1.565 & 371.27 & 371.91 & 260.21 & 260.48 & 3523.57 & 3503.22 \\
\hline 22 & 0 & -1.565 & 0 & 0 & 0 & 0 & 358.37 & 359.06 & 245.01 & 245.66 & 3684.53 & 3675.18 \\
\hline 23 & -1 & -1 & -1 & -1 & 1 & -1 & 339.12 & 338.99 & 213.99 & 213.76 & 3351.78 & 3350.49 \\
\hline 24 & 0 & 0 & 0 & -1.565 & 0 & 0 & 360.28 & 361.4 & 245.25 & 246.3 & 3874.73 & 3865.7 \\
\hline 25 & 1 & 1 & -1 & 1 & 1 & 1 & 380.83 & 380.7 & 257.32 & 257.38 & 3452.85 & 3455.58 \\
\hline 26 & 1 & -1 & -1 & 1 & -1 & 1 & 368.34 & 368.23 & 246.92 & 246.9 & 3174.18 & 3177.1 \\
\hline 27 & 1 & 1 & -1 & -1 & -1 & -1 & 348.39 & 347.85 & 233.55 & 233.11 & 3012.75 & 3012.37 \\
\hline 28 & -1 & -1 & -1 & -1 & -1 & 1 & 346.37 & 346.27 & 225.5 & 225.3 & 3148.66 & 3150.42 \\
\hline 29 & -1 & -1 & 1 & 1 & 1 & -1 & 335.24 & 335.11 & 218.37 & 218.22 & 3975.12 & 3975.87 \\
\hline 30 & 0 & 0 & 0 & 0 & 0 & -1.565 & 346.36 & 347.42 & 233.43 & 234.48 & 3296.38 & 3299.21 \\
\hline 31 & -1 & -1 & 1 & -1 & 1 & 1 & 337.83 & 337.69 & 225.45 & 225.3 & 4869.77 & 4873.61 \\
\hline 32 & 1 & -1 & -1 & 1 & 1 & -1 & 362.98 & 362.84 & 244.43 & 244.39 & 3429.48 & 3429.35 \\
\hline 33 & -1 & 1 & -1 & -1 & 1 & 1 & 358.52 & 358.4 & 225.74 & 225.61 & 3321.11 & 3322.69 \\
\hline 34 & 0 & 0 & -1.565 & 0 & 0 & 0 & 351.29 & 351.89 & 239.46 & 240.03 & 2735.98 & 2735.3 \\
\hline 35 & 0 & 0 & 0 & 1.565 & 0 & 0 & 366.25 & 366.83 & 253.11 & 253.38 & 3346.24 & 3337.75 \\
\hline 36 & -1 & 1 & -1 & 1 & -1 & 1 & 362.54 & 362.47 & 235.13 & 235.03 & 3242.57 & 3244.1 \\
\hline 37 & 0 & 0 & 0 & 0 & 0 & 0 & 366.28 & 363.88 & 256.45 & 255.32 & 3326.45 & 3290.22 \\
\hline 38 & 0 & 1.565 & 0 & 0 & 0 & 0 & 371.37 & 372.37 & 255.22 & 255.89 & 3305.22 & 3297.06 \\
\hline 39 & 1 & -1 & 1 & 1 & 1 & 1 & 361.45 & 361.3 & 240.1 & 240.14 & 4632.14 & 4637.14 \\
\hline 40 & 0 & 0 & 0 & 0 & 0 & 0 & 367.21 & 363.88 & 255.71 & 255.32 & 3244.83 & 3290.22 \\
\hline
\end{tabular}

$x_{1}, x_{2}, x_{3}, x_{4}, x_{5}$ and $x_{6}=$ model codes for molasses, corn steep liquor, asparagine, potassium ions, manganese (II) ions and chromium (III) ions respectively; $\mathrm{eY}_{1}=$ Experimental biomass concentration $(\mathrm{g} / \mathrm{L}) ; \mathrm{pY}_{1}=$ Predicted biomass concentration $(\mathrm{g} / \mathrm{L})$; eY $\mathrm{Y}_{2}=$ experimental total protein $(\mathrm{mg}) ; \mathrm{pY}_{2}=$ Predicted total protein $(\mathrm{mg}) ; \mathrm{eY}_{3}=$ experimental L-asparaginase activity $(\mathrm{U}) ; \mathrm{pY}_{3}=$ Predicted L-asparaginase activity $(\mathrm{U}) ;$ Values of responses are means of triplicate determinations.

RSM Modeling for Improved L-Asparaginase Activity in Aspergillus candidus UCCM 00117

In addition to L-asparaginase activity $\left(\mathrm{Y}_{3}\right)$, two more responses were measured during the RSM experimentation namely biomass concentration $\left(\mathrm{Y}_{1}\right)$ and total protein $\left(\mathrm{Y}_{2}\right)$ to enable the determination of specific activity of the enzyme and yield coefficient of the process. The design matrix, experimental and predicted responses are presented in Table 4. The table shows that maximum biomass 
Table 5 Analysis of variance (ANOVA) for reduced quadratic regression model of biomass concentration $\left(\mathrm{Y}_{1}\right)$

\begin{tabular}{|c|c|c|c|c|c|}
\hline Source & Sum of squares & df & Mean square & $F$-value & $p$-value \\
\hline Model & 5335.32 & 19 & 280.81 & 82.17 & $<0.0001$ \\
\hline $\mathrm{X}_{1}$-molasses & 1290.71 & 1 & 1290.71 & 377.7 & $<0.0001$ \\
\hline $\mathrm{X}_{2}$-corn steep liquor & 384.91 & 1 & 384.91 & 112.64 & $<0.0001$ \\
\hline $\mathrm{X}_{3}$-asparagine & 16.99 & 1 & 16.99 & 4.97 & 0.0374 \\
\hline $\mathrm{X}_{4}-\mathrm{K}^{+}$ & 84.87 & 1 & 84.87 & 24.83 & $<0.0001$ \\
\hline $\mathrm{X}_{5}-\mathrm{Mn}^{2+}$ & 77.09 & 1 & 77.09 & 22.56 & 0.0001 \\
\hline $\mathrm{X}_{6}-\mathrm{Cr}^{3+}$ & 1365.27 & 1 & 1365.27 & 399.52 & $<0.0001$ \\
\hline $\mathrm{X}_{1} \mathrm{X}_{2}$ & 16.23 & 1 & 16.23 & 4.75 & 0.0415 \\
\hline$X_{1} X_{3}$ & 27.36 & 1 & 27.36 & 8.01 & 0.0104 \\
\hline $\mathrm{X}_{1} \mathrm{X}_{4}$ & 52.61 & 1 & 52.61 & 15.4 & 0.0008 \\
\hline $\mathrm{X}_{1} \mathrm{X}_{6}$ & 24.38 & 1 & 24.38 & 7.13 & 0.0147 \\
\hline $\mathrm{X}_{2} \mathrm{X}_{3}$ & 52.17 & 1 & 52.17 & 15.27 & 0.0009 \\
\hline $\mathrm{X}_{2} \mathrm{X}_{4}$ & 94.67 & 1 & 94.67 & 27.7 & $<0.0001$ \\
\hline $\mathrm{X}_{2} \mathrm{X}_{5}$ & 17.62 & 1 & 17.62 & 5.16 & 0.0344 \\
\hline $\mathrm{X}_{2} \mathrm{X}_{6}$ & 306.78 & 1 & 306.78 & 89.77 & $<0.0001$ \\
\hline$X_{3} X_{4}$ & 89.57 & 1 & 89.57 & 26.21 & $<0.0001$ \\
\hline$X_{3} X_{5}$ & 56.62 & 1 & 56.62 & 16.57 & 0.0006 \\
\hline $\mathrm{X}_{3}^{2}$ & 384.93 & 1 & 384.93 & 112.64 & $<0.0001$ \\
\hline $\mathrm{X}_{5}^{2}$ & 219.01 & 1 & 219.01 & 64.09 & $<0.0001$ \\
\hline $\mathrm{X}_{6}^{2}$ & 37.08 & 1 & 37.08 & 10.85 & 0.0036 \\
\hline Residual & 68.35 & 20 & 3.42 & & \\
\hline Lack-of-fit & 48.33 & 15 & 3.22 & 0.805 & 0.6617 \\
\hline Pure error & 20.01 & 5 & 4 & & \\
\hline Cor total & 5403.67 & 39 & & & \\
\hline
\end{tabular}

$r^{2}=0.9874$; Adjusted $r^{2}=0.9753$; Predicted $r^{2}=0.9269$; Standard deviation=1.85; Mean=357.24; C.V. $\%=0.5175 ;$ Adequate precision $=40.37 ; \mathrm{PRESS}=395.21 ; \mathrm{BIC}=208.72 ; \mathrm{AICc}=219.15$ concentration, $\mathrm{Y}_{1}$ of $87.91 \mathrm{~g} / \mathrm{L}$ (predicted as $87.34 \mathrm{~g} / \mathrm{L}$ ) was obtained in run 5 where molasses, corn steep liquor, asparagine and $\mathrm{Cr}^{3+}$ were at their high levels $(+1)$, with $\mathrm{K}^{+}$and $\mathrm{Mn}^{2+}$ at their low levels $(-1)$. This run also accounted for highest total protein, $\mathrm{Y}_{2}$ of $65.39 \mathrm{mg}$ (predicted as $65.11 \mathrm{mg}$ ) indicating strong significant positive correlation $(r=0.8747, p<0.0001)$ between the two responses. Highest L-asparaginase activity $\left(\mathrm{Y}_{3}\right)$ of $4924.78 \mathrm{U}$ (predicted as 4927.74 U) was recorded for run 1 where corn steep liquor, asparagine and $\mathrm{K}^{+}$were at their low levels while molasses, $\mathrm{Mn}^{2+}$ and $\mathrm{Cr}^{3+}$ were at their high levels. Conversely, lowest L-asparaginase activity of $2735.98 \mathrm{U}$ (predicted as 2735.3 $\mathrm{U})$ was observed in run 34 where all predictors were held at their center points $(0)$ except asparagine which was supplied at its lowest or axial level (-1.56508).

Analysis of variance (ANOVA) for biomass concentration $\left(\mathrm{Y}_{1}\right)$ model is presented as a reduced model containing only significant predictors of the response, $\mathrm{Y}_{1}$ obtained by backward elimination method (Table 5). From the table, it is observed that the modified model was significant $\left(F=82.17\right.$, adjusted $r^{2}=0.9753$, predicted $\left.r^{2}=0.9269, p<0.0001\right)$ and adequate to explain variations about the data within the experimental region as evaluated by its non-significant lack-of-fit (LoF) test value of $F$ (15, $20)=0.805, p=0.6617>0.05$. The diagnostic plot of actual versus predicted $Y_{1}$ plot (Fig. 4a) further confirms the adequacy of the model. Coefficients of the predictors were employed to build the reduced second-order regression function for biomass concentration as follows:

$$
\begin{aligned}
Y_{1}= & 63.88+7.64 X_{1}+4.25 X_{2}+1.73 X_{4} \\
& -2.03 X_{5}+7.82 X_{6}+1.11 X_{1} X_{3}+1.83 X_{1} X_{4} \\
& +1.20 X_{1} X_{6}+1.46 X_{2} X_{3}-2.05 X_{2} X_{4}+4.24 X_{2} X_{6} \\
& -1.98 X_{3} X_{4}-1.67 X_{3} X_{5}-5.31 X_{3}^{2}-4.03 X_{5}^{2}-1.72 X_{6}^{2}
\end{aligned}
$$

Analysis of variance (ANOVA) for total protein $\left(\mathrm{Y}_{2}\right)$ model is also presented as a reduced quadratic function that discriminated against non-significant predictor terms through backward elimination (Table 6). Out of the 27 terms required to build the full model, 5 terms with non-significant $(p>0.05) F$-value were eliminated. The reduced model was significant at $F=269.35$, adjusted $r^{2}=0.9934$, predicted $r^{2}=0.9803, p<0.0001$. The non-significant LoF test value of $F(12,17)=1.97, p=0.2352>0.05$ indicated adequacy of the model. The goodness-of-fit, $r^{2}$ of experimental versus predicted $\mathrm{Y}_{2}$ plot (Fig. 4b) was also in reasonable agreement 

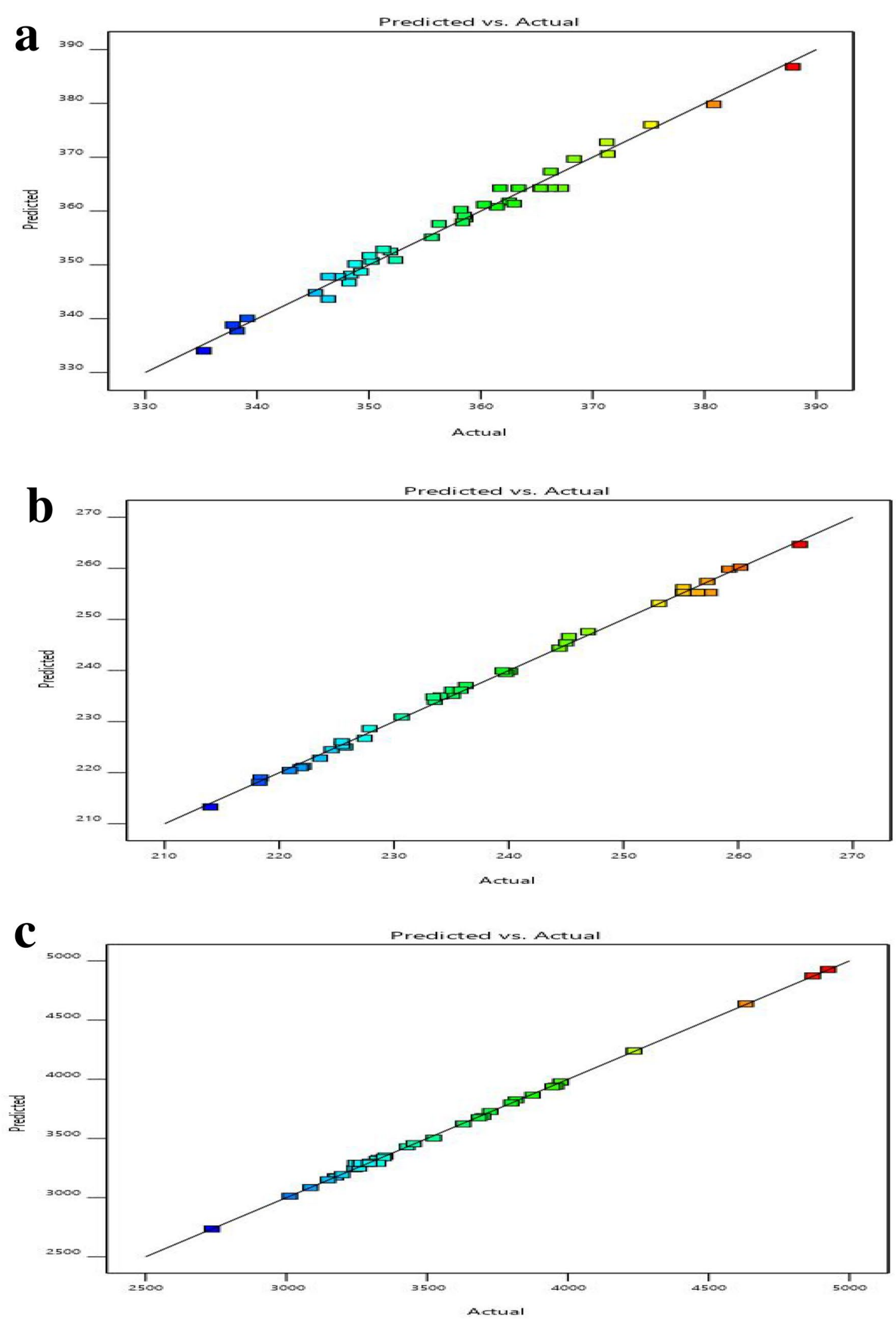

Fig. 4 Experimental versus predicted response surface methodology plots to evaluate the adequacy of a biomass concentration $\mathbf{b}$ total protein $\mathbf{c}$ L-asparaginase activity second-order regression models 
Table 6 Analysis of variance (ANOVA) for reduced quadratic regression model of total protein $\left(\mathrm{Y}_{2}\right)$

\begin{tabular}{|c|c|c|c|c|c|}
\hline Source & Sum of squares & $\mathrm{df}$ & Mean square & $F$-value & $p$-value \\
\hline Model & 8092.77 & 22 & 367.85 & 269.35 & $<0.0001$ \\
\hline $\mathrm{X}_{1}$-molasses & 1118.34 & 1 & 1118.34 & 818.87 & $<0.0001$ \\
\hline $\mathrm{X}_{2}$-corn steep liquor & 266.48 & 1 & 266.48 & 195.13 & $<0.0001$ \\
\hline $\mathrm{X}_{3}$-asparagine & 52.27 & 1 & 52.27 & 38.28 & $<0.0001$ \\
\hline $\mathrm{X}_{4}-\mathrm{K}^{+}$ & 93.92 & 1 & 93.92 & 68.77 & $<0.0001$ \\
\hline $\mathrm{X}_{6}-\mathrm{Cr}^{3+}$ & 1400.88 & 1 & 1400.88 & 1025.76 & $<0.0001$ \\
\hline $\mathrm{X}_{1} \mathrm{X}_{2}$ & 126.78 & 1 & 126.78 & 92.83 & $<0.0001$ \\
\hline $\mathrm{X}_{1} \mathrm{X}_{4}$ & 42.32 & 1 & 42.32 & 30.98 & $<0.0001$ \\
\hline $\mathrm{X}_{1} \mathrm{X}_{5}$ & 22.64 & 1 & 22.64 & 16.58 & 0.0008 \\
\hline $\mathrm{X}_{2} \mathrm{X}_{3}$ & 14.1 & 1 & 14.1 & 10.32 & 0.0051 \\
\hline $\mathrm{X}_{2} \mathrm{X}_{4}$ & 98.41 & 1 & 98.41 & 72.06 & $<0.0001$ \\
\hline $\mathrm{X}_{2} \mathrm{X}_{5}$ & 53.02 & 1 & 53.02 & 38.82 & $<0.0001$ \\
\hline $\mathrm{X}_{2} \mathrm{X}_{6}$ & 54.33 & 1 & 54.33 & 39.78 & $<0.0001$ \\
\hline $\mathrm{X}_{3} \mathrm{X}_{4}$ & 338.45 & 1 & 338.45 & 247.82 & $<0.0001$ \\
\hline $\mathrm{X}_{3} \mathrm{X}_{6}$ & 14.19 & 1 & 14.19 & 10.39 & 0.005 \\
\hline $\mathrm{X}_{4} \mathrm{X}_{5}$ & 201.44 & 1 & 201.44 & 147.5 & $<0.0001$ \\
\hline $\mathrm{X}_{5} \mathrm{X}_{6}$ & 64.25 & 1 & 64.25 & 47.04 & $<0.0001$ \\
\hline $\mathrm{X}_{1}^{2}$ & 104.21 & 1 & 104.21 & 76.31 & $<0.0001$ \\
\hline $\mathrm{X}_{2}^{2}$ & 44.3 & 1 & 44.3 & 32.44 & $<0.0001$ \\
\hline $\mathrm{X}_{3}^{2}$ & 709.25 & 1 & 709.25 & 519.33 & $<0.0001$ \\
\hline $\mathrm{X}_{4}^{2}$ & 64.88 & 1 & 64.88 & 47.5 & $<0.0001$ \\
\hline $\mathrm{X}_{5}^{2}$ & 818.31 & 1 & 818.31 & 599.19 & $<0.0001$ \\
\hline $\mathrm{X}_{6}^{2}$ & 134.2 & 1 & 134.2 & 98.27 & $<0.0001$ \\
\hline Residual & 23.22 & 17 & 1.37 & & \\
\hline Lack-of-fit & 19.16 & 12 & 1.6 & 1.97 & 0.2352 \\
\hline Pure error & 4.06 & 5 & 0.8119 & & \\
\hline Cor total & 8115.99 & 39 & & & \\
\hline
\end{tabular}

$r^{2}=0.9971 ;$ Adjusted $r^{2}=0.9934$; Predicted $r^{2}=0.9803$; Standard deviation=1.17; Mean=238.94; C.V. $\%=0.4891 ;$ Adequate precision $=57.98 ; \mathrm{PRESS}=160.23 ; \mathrm{BIC}=176.60 ; \mathrm{AICc}=206.76$ with the model $r^{2}$ value of 0.9971 , thus validating the adequacy of the model. Model coefficient terms were used to build the second-order polynomial equation for $\mathrm{Y}_{2}$ as follows:

$$
\begin{aligned}
Y_{2}= & 55.27+7.27 X_{1}+3.45 X_{2}-1.57 X_{3}+2.07 X_{4} \\
& +8.17 X_{6}+2.62 X_{1} X_{2}+1.52 X_{1} X_{4}-1.13 X_{1} X_{5} \\
& +0.8729 X_{2} X_{3}-2.28 X_{2} X_{4}-1.70 X_{2} X_{5} \\
& +1.71 X_{2} X_{6}-4.32 X_{3} X_{4}+0.8929 X_{3} X_{6} \\
& +3.34 X_{4} X_{5}-1.91 X_{5} X_{6}-2.79 X_{1}^{2}-1.82 X_{2}^{2} \\
& -7.27 X_{3}^{2}-2.20 X_{4}^{2}-7.81 X_{5}^{2}-3.16 X_{6}^{2}
\end{aligned}
$$

The ANOVA for L-asparaginase activity regression model $\left(\mathrm{Y}_{3}\right)$ is presented as a full quadratic function in Table 7. All 27 predictors of the second-order function of 6 factors were significant for $\mathrm{Y}_{3}$ and the model's $F$-value of 649.96 was also significant $(p<0.0001)$. The difference between adjusted and predicted goodness-of-fit, $r^{2}$ of 0.9978 and 0.9909 respectively, was not more than 0.2 suggesting that the model was adequate for predictions (Fig. 4c). The LoF
Fischer-ratio statistic of $F(7,12)=0.3965$ was not significant $(p=0.8701>0.05)$ suggesting that whatever component of the proposed quadratic model that may have lacked fit was not important enough to alter the predicted L-asparaginase activity value. The model is presented as Eq. 13 below.

$$
\begin{aligned}
Y_{3}= & 3290.22+156.74 X_{1}-120.80 X_{2}+385.51 X_{3}-168.67 X_{4} \\
& +219.66 X_{5}+65.18 X_{6}-123.68 X_{1} X_{2}-27.84 X_{1} X_{3}-82.78 X_{1} X_{4} \\
& +94.40 X_{1} X_{5}+82.44 X_{1} X_{6}-24.80 X_{2} X_{3}+150.70 X_{2} X_{4} \\
& -90.14 X_{2} X_{5}-21.49 X_{2} X_{6}-37.49 X_{3} X_{4}+87.61 X_{3} X_{5} \\
& -22.43 X_{3} X_{6}-94.86 X_{4} X_{5}-95.95 X_{4} X_{6}+98.14 X_{5} X_{6} \\
& +61.08 X_{1}^{2}+79.98 X_{2}^{2}+19.77 X_{3}^{2}+127.17 X_{4}^{2}+123.73 X_{5}^{2}+45.32 X_{6}^{2}
\end{aligned}
$$

The L-asparaginase activity model predictor coefficients inform about the magnitude of contributions of the predictors to the model while the signs indicate the direction of the contribution or effect of the predictor. Equation 13 reveals that asparagine $\left(\mathrm{X}_{3}\right)$ and $\mathrm{Mn}^{2+}\left(\mathrm{X}_{5}\right)$ made the largest linear contribution to predicted $\mathrm{L}$-asparaginase 
Table 7 Analysis of variance (ANOVA) for the full quadratic model of L-asparaginase activity $\left(\mathrm{Y}_{3}\right)$

\begin{tabular}{|c|c|c|c|c|c|}
\hline Source & Sum of squares & df & Mean square & $F$-value & $p$-value \\
\hline Model & $9.39 \mathrm{E}+06$ & 27 & $3.48 \mathrm{E}+05$ & 649.96 & $<0.0001$ \\
\hline $\mathrm{X}_{1}$-molasses & $4.56 \mathrm{E}+05$ & 1 & $4.56 \mathrm{E}+05$ & 852.66 & $<0.0001$ \\
\hline $\mathrm{X}_{2}$-corn steep liquor & $2.71 \mathrm{E}+05$ & 1 & $2.71 \mathrm{E}+05$ & 506.48 & $<0.0001$ \\
\hline $\mathrm{X}_{3}$-asparagine & $2.76 \mathrm{E}+06$ & 1 & $2.76 \mathrm{E}+06$ & 5158.31 & $<0.0001$ \\
\hline $\mathrm{X}_{4}-\mathrm{K}^{+}$ & $5.29 \mathrm{E}+05$ & 1 & $5.29 \mathrm{E}+05$ & 987.39 & $<0.0001$ \\
\hline $\mathrm{X}_{5}-\mathrm{Mn}^{2+}$ & $8.97 \mathrm{E}+05$ & 1 & $8.97 \mathrm{E}+05$ & 1674.7 & $<0.0001$ \\
\hline $\mathrm{X}_{6}-\mathrm{Cr}^{3+}$ & $78,926.2$ & 1 & $78,926.2$ & 147.44 & $<0.0001$ \\
\hline $\mathrm{X}_{1} \mathrm{X}_{2}$ & $2.56 \mathrm{E}+05$ & 1 & $2.56 \mathrm{E}+05$ & 477.76 & $<0.0001$ \\
\hline $\mathrm{X}_{1} \mathrm{X}_{3}$ & $12,958.3$ & 1 & $12,958.3$ & 24.21 & 0.0004 \\
\hline $\mathrm{X}_{1} \mathrm{X}_{4}$ & $1.15 \mathrm{E}+05$ & 1 & $1.15 \mathrm{E}+05$ & 214 & $<0.0001$ \\
\hline $\mathrm{X}_{1} \mathrm{X}_{5}$ & $1.49 \mathrm{E}+05$ & 1 & $1.49 \mathrm{E}+05$ & 278.33 & $<0.0001$ \\
\hline $\mathrm{X}_{1} \mathrm{X}_{6}$ & $1.14 \mathrm{E}+05$ & 1 & $1.14 \mathrm{E}+05$ & 212.26 & $<0.0001$ \\
\hline $\mathrm{X}_{2} \mathrm{X}_{3}$ & $10,278.95$ & 1 & $10,278.95$ & 19.2 & 0.0009 \\
\hline $\mathrm{X}_{2} \mathrm{X}_{4}$ & $3.80 \mathrm{E}+05$ & 1 & $3.80 \mathrm{E}+05$ & 709.25 & $<0.0001$ \\
\hline $\mathrm{X}_{2} \mathrm{X}_{5}$ & $1.36 \mathrm{E}+05$ & 1 & $1.36 \mathrm{E}+05$ & 253.74 & $<0.0001$ \\
\hline $\mathrm{X}_{2} \mathrm{X}_{6}$ & 7722.39 & 1 & 7722.39 & 14.43 & 0.0025 \\
\hline $\mathrm{X}_{3} \mathrm{X}_{4}$ & $23,493.29$ & 1 & $23,493.29$ & 43.89 & $<0.0001$ \\
\hline$X_{3} X_{5}$ & $1.28 \mathrm{E}+05$ & 1 & $1.28 \mathrm{E}+05$ & 239.74 & $<0.0001$ \\
\hline$X_{3} X_{6}$ & 8412.16 & 1 & 8412.16 & 15.71 & 0.0019 \\
\hline $\mathrm{X}_{4} \mathrm{X}_{5}$ & $1.50 \mathrm{E}+05$ & 1 & $1.50 \mathrm{E}+05$ & 281.05 & $<0.0001$ \\
\hline $\mathrm{X}_{4} \mathrm{X}_{6}$ & $1.54 \mathrm{E}+05$ & 1 & $1.54 \mathrm{E}+05$ & 287.49 & $<0.0001$ \\
\hline $\mathrm{X}_{5} \mathrm{X}_{6}$ & $1.61 \mathrm{E}+05$ & 1 & $1.61 \mathrm{E}+05$ & 300.8 & $<0.0001$ \\
\hline $\mathrm{X}_{1}^{2}$ & $49,744.54$ & 1 & $49,744.54$ & 92.93 & $<0.0001$ \\
\hline $\mathrm{X}_{2}^{2}$ & $85,295.11$ & 1 & $85,295.11$ & 159.34 & $<0.0001$ \\
\hline$X_{3}^{2}$ & 5213.79 & 1 & 5213.79 & 9.74 & 0.0088 \\
\hline $\mathrm{X}_{4}^{2}$ & $2.16 \mathrm{E}+05$ & 1 & $2.16 \mathrm{E}+05$ & 402.91 & $<0.0001$ \\
\hline $\mathrm{X}_{5}^{2}$ & $2.04 \mathrm{E}+05$ & 1 & $2.04 \mathrm{E}+05$ & 381.4 & $<0.0001$ \\
\hline$X_{6}^{2}$ & $27,383.95$ & 1 & $27,383.95$ & 51.16 & $<0.0001$ \\
\hline Residual & 6423.58 & 12 & 535.3 & & \\
\hline Lack-of-fit & 2293.1 & 7 & 327.59 & 0.3965 & 0.8701 \\
\hline Pure error & 4130.48 & 5 & 826.1 & & \\
\hline Cor Total & $9.40 \mathrm{E}+06$ & 39 & & & \\
\hline
\end{tabular}

$r^{2}=0.9993 ;$ Adjusted $r^{2}=0.9978 ;$ Predicted $r^{2}=0.9909 ;$ Standard deviation $=23.14 ;$ Meana $=3576.08$; C.V. $\%=0.6470 ;$ Adequate precision $=113.26 ; \mathrm{PRESS}=85,742.41 ; \mathrm{BIC}=419.96 ; \mathrm{AICc}=520.31$ activity. Their contributions were positive suggesting that they enhanced the activity of the enzyme. Corn steep liquor and $\mathrm{K}^{+}$, on the other hand, had the largest negative coefficients in the model suggesting they largely inhibited L-asparaginase activity. The largest positive interaction coefficient is that for corn steep liquor and asparagine $\left(\mathrm{X}_{2} \mathrm{X}_{3}\right)$ which enhanced L-asparaginase activity. Contrariwise, the interaction between molasses and corn steep liquor $\left(\mathrm{X}_{1} \mathrm{X}_{2}\right)$ and that between $\mathrm{K}^{+}$and $\mathrm{Mn}^{2+}\left(\mathrm{X}_{4} \mathrm{X}_{5}\right)$ had the largest negative coefficients and so largely reduced the activity of the enzyme. All the quadratic terms of the model contributed towards improved L-asparaginase activity with $\mathrm{K}^{+}$and $\mathrm{Mn}^{2+}$ making the highest contributions to the improvement. This position is the complete opposite for $\mathrm{Y}_{1}$ and $\mathrm{Y}_{2}$ models where quadratic terms of their models only reduced the respective responses.

Interaction model predictors for all three responses are presented as surface (3-D) plots in Fig. 5. Figure 5a reveals that highest predicted concentration of fungal biomass would be $378.69 \mathrm{~g} / \mathrm{L}$ if levels of corn steep liquor and $\mathrm{Cr}^{3+}$ were adjusted to $0.995(70.96 \%)$ and $0.992(51.95 \mathrm{mg} / \mathrm{L})$ in natural units respectively, with the remaining 4 predictors held at their center points. Highest interaction term contribution to total protein was also by corn steep liquor and $\mathrm{Cr}^{3+}$ when their levels were adjusted to 0.984 and 0.996 respectively (Fig. 5b) corresponding to $70.92 \%$ and $51.97 \mathrm{mg} / \mathrm{L}$ respectively, in natural units. This lends credence to the strong significant positive relationship between biomass 

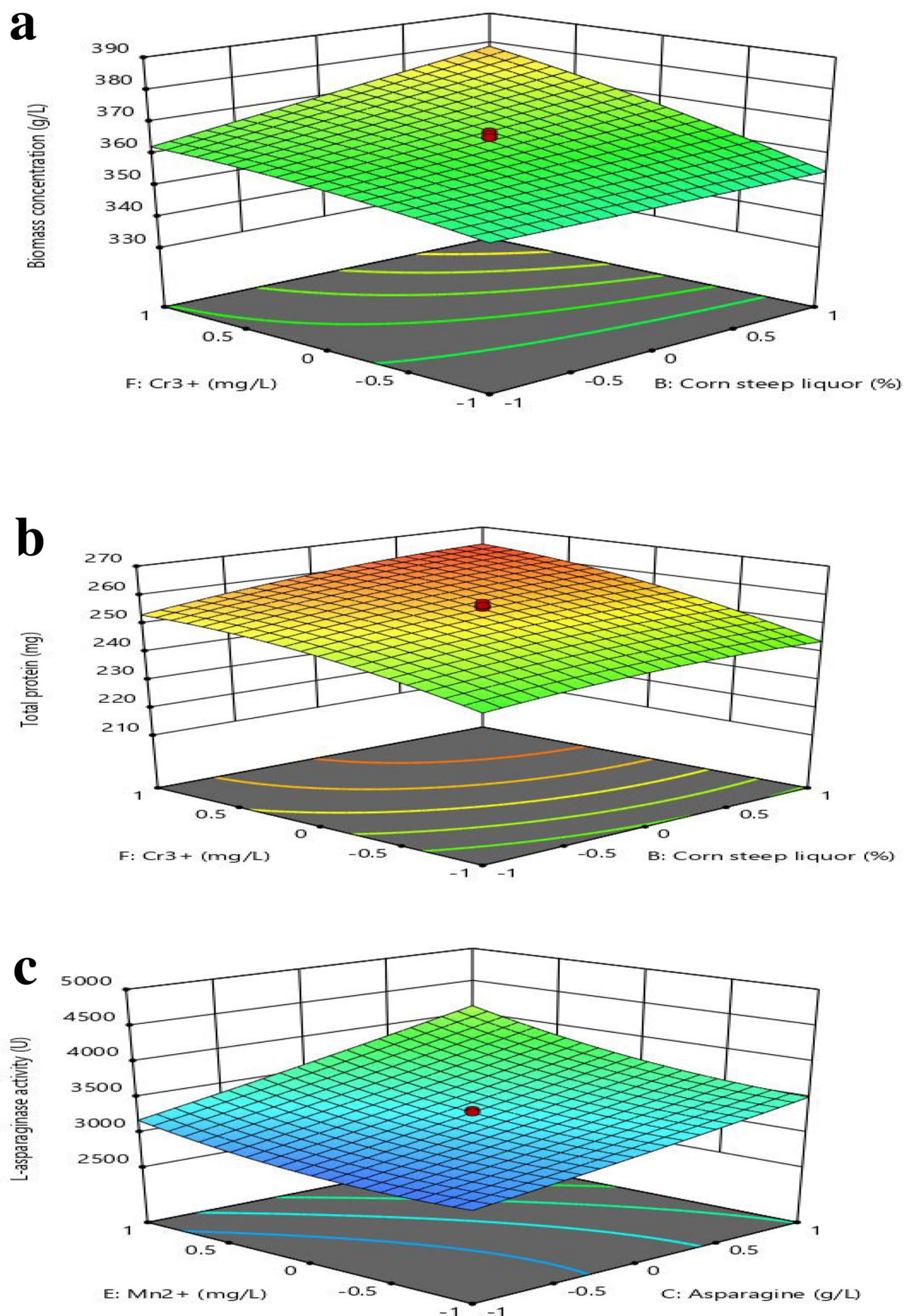

Fig. 5 Surface plots of most significant two-way factor interactions towards maximum a biomass concentration $\mathbf{b}$ total protein and $\mathbf{c}$ L-asparaginase activity 
concentration and total protein $(r=0.8747)$. Figure $5 \mathrm{c}$ is the surface plot for most significant two-way interaction of predictors towards enhanced L-asparaginase activity. The figure shows that L-asparaginase activity will be as high as 4124.6 $\mathrm{U}$ if levels of both asparagine and $\mathrm{Mn}^{2+}$ would be adjusted to 0.988 which would correspond to $44.22 \mathrm{~g} / \mathrm{L}$ and $54.99 \mathrm{mg} / \mathrm{L}$ respectively, in natural units while all other factors are held at their center points.

\section{Multi-objective Optimization of Responses Using the Desirability Function}

Biomass concentration $\left(\mathrm{Y}_{1}\right)$ and total protein $\left(\mathrm{Y}_{2}\right)$ are by themselves significant predictors of $\mathrm{L}$-asparaginase concentration, and by extension its activity $\left(\mathrm{Y}_{3}\right)$. The total activity of an enzyme is not nearly as important as its specific activity; calculated as a ratio of total enzyme activity to the amount of total protein. Similarly, the yield coefficient (yield of product on biomass), $\mathrm{Yp} / \mathrm{x}$, of a microbial fermentation
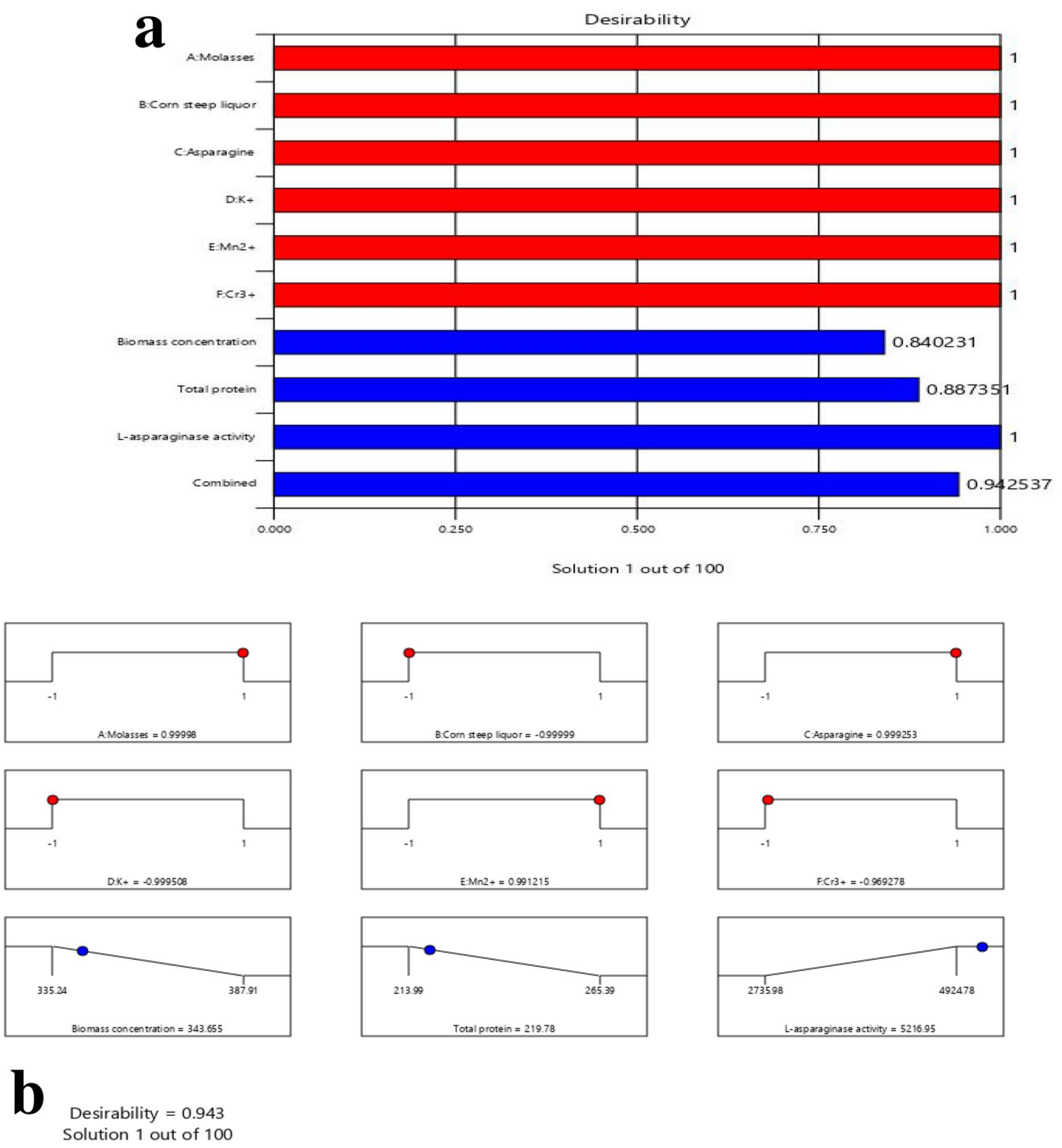

Fig. 6 Multi-objective plots for optimization of bioprocess nutrient levels towards enhanced L-asparaginase activity. a The bar graph of desirability plot showing individual response desirability and recommended composite (combined) desirability when all factors were given maximum desirability of 1 . b The ramp plot showing final factor settings and the responses obtained at the composite desirability recommended 

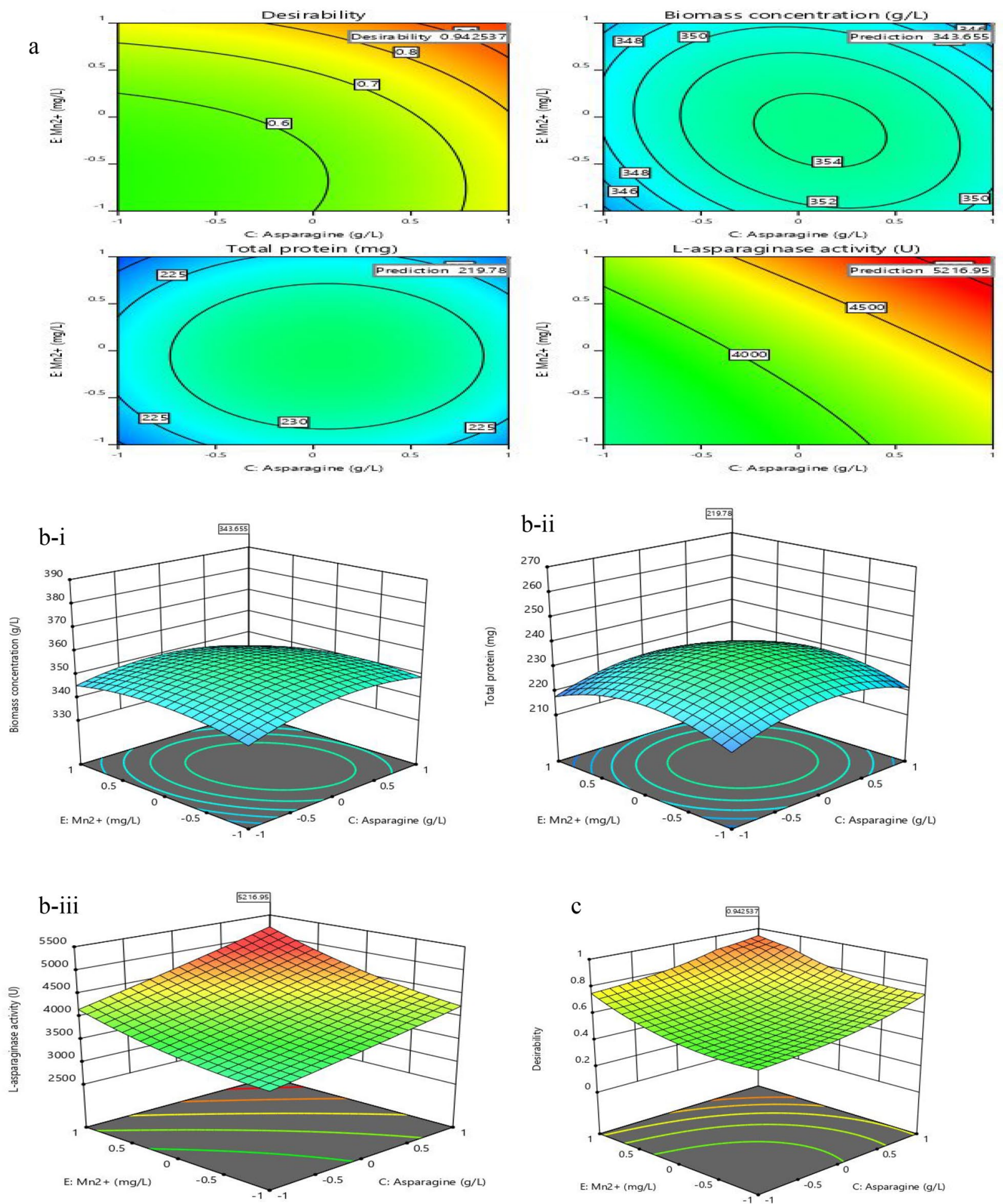

Fig. 7 Contour and surface plots of multi-objective optimal solutions for fermentation responses a A 4-in-1 contour plot of asparagine/ $\mathrm{Mn}^{2+}$ interaction towards minimum biomass concentration, minimum total protein and maximum L-asparaginase. b-i Surface plot for mini-

mum biomass concentration. b-ii Surface plot for minimum total protein. b-iii Surface plot for maximum L-asparaginase activity. c Surface plot for the composite desirability for maximum L-asparaginase activity 
product is calculated in relation to the concentration of biomass that synthesized it. Since the two goals of specific activity and yield coefficient would only be enhanced at high L-asparaginase activity and concentration respectively, it became imperative to search for predictor levels that would maximize L-asparaginase concentration and its activity, while keeping the denominators at minimum levels. The goals of the multi-objective optimization were therefore set to minimize both $Y_{1}$ and $Y_{2}$ while maximizing $Y_{3}$. Secondly, all the factors and responses were held at equal weight of 1 but with variable scaling of the importance of the three responses. A scale of lindicated least importance while 5 indicated most importance. Results showed that a scaling of importance of 1,3 and 5 for $Y_{1}, Y_{2}$ and $Y_{3}$ respectively was most appropriate since it produced the highest composite desirability for the study. The desirability of each response was calculated as 0.840 for $\mathrm{Y}_{1}, 0.887$ for $\mathrm{Y}_{2}$ and 1.000 for $\mathrm{Y}_{3}$ (Fig. 6a). A composite desirability, $D$, solved from Eq. 6 was calculated as 0.943 by adjusting levels of predictors to minimize $Y_{1}$ and $Y_{2}$ while maximizing $Y_{3}$. The optimal solution given by the multi-objective optimization was therefore $0.99998,-0.99999,0.999253,-0.999508$, $0.991215,-0.969278$ for $\mathrm{X}_{1}, \mathrm{X}_{2}, \mathrm{X}_{3}, \mathrm{X}_{4}, \mathrm{X}_{5}, \mathrm{X}_{6}$ respectively (Fig. 6b). These levels corresponded to $49.55 \mathrm{~g} / \mathrm{L}$ molasses, $64.98 \%$ corn steep liquor, $44.23 \mathrm{~g} / \mathrm{L}$ asparagine, $1.73 \mathrm{~g} / \mathrm{L}$ $\mathrm{K}^{+}, 0.055 \mathrm{~g} / \mathrm{L} \mathrm{Mn}^{2+}$ and $0.043 \mathrm{~g} / \mathrm{L} \mathrm{Cr}^{3+}$ in natural units. These conditions resulted in a biomass concentration of $343.655 \mathrm{~g} / \mathrm{L}$, total protein of $219.78 \mathrm{mg}$ and L-asparaginase activity of $5216.945 \mathrm{U}$. The contour, surface and desirability plots in Fig. 7 are graphical representations of the optimized solutions for the responses described.

\section{Validation Experiments for Multi-objective Response Surface Optimization}

The triplicate confirmation experiments set up to verify the optimal settings by the multi-objective function towards maximum L-asparaginase activity produced $344.76 \pm 23.74 \mathrm{~g} / \mathrm{L}$ fungal biomass, $218.53 \pm 19.59 \mathrm{mg}$ total protein and an L-asparaginase activity of $5187.65 \pm 184.38 \mathrm{U}$.
These results gave a yield coefficient, $\mathrm{Yp} / \mathrm{x}$, of $15.05 \mathrm{U} /(\mathrm{g} / \mathrm{L})$ and a specific activity of $23.74 \mathrm{U} / \mathrm{mg}$. When these results were compared to the suggestions by the multi-objective function, it was found that none of the corresponding differences was greater than 5\% indicating that the optimal conditions suggested by the optimizer were in reasonable agreement with real life situations.

\section{Purification, Activity and Fold Determinations of Aspergillus candidus UCCM 00117 L-Asparaginase}

Results of purification, activity and fold determinations of the L-asparaginase obtained by fermentation of Aspergillus candidus UCCM 00117 in the optimized medium is summarized in Table 8 . The table shows that enzyme purity, expressed in terms of fold, increased with each purification step until a final enzyme with $\sim 20$-fold purity was obtained. On the contrary, L-asparaginase yield (\%) or recovery decreased with every step of the purification process until a final yield of $36.46 \%$ of the enzyme, corresponding to $1.45 \mathrm{mg}$ of a final total protein of $3.97 \mathrm{mg}$ was obtained. L-asparaginase yield by Streptomyces rochei subsp. chromatogens NEAE-K reported by El-Naggar and El-Shweihy (2020) from a similar optimization study was 30\%, although with lower fold of purification. The L-glutaminase activity of the enzyme also decreased from an initial activity of $82.131 \mathrm{U}$ in the sterile broth to a final activity of $0.087 \mathrm{U}$, when L-asparaginase activity was $1891.64 \mathrm{U}$ with a specific activity of $476.48 \mathrm{U} / \mathrm{mg}$. Since potent L-asparaginases in anti-cancer drug formulations possess a range of untoward reactions due to glutaminase activity, Aspergillus candidus UCCM $00117 \mathrm{~L}$-asparaginase holds promise for very minimal toxicity during therapy.

Literature is replete with reports on microbial production and anti-cancer activities of glutaminase-free L-asparaginase (Hussain et al. 2016; El-Naggar et al. 2018; Ashok et al. 2019). However, research is not very clear on the role of glutaminase activity during L-asparaginase treatment of human cancers. Glutaminase activity of L-asparaginase may not be required for anti-cancer activity in asparaginase

Table 8 Effects of purification steps on total protein, activities, yield and fold of Aspergillus candidus UCCM 00117 L-asparaginase

\begin{tabular}{|c|c|c|c|c|c|c|}
\hline \multirow[t]{2}{*}{ Purification step } & \multirow[t]{2}{*}{ Total protein (mg) } & \multicolumn{2}{|l|}{ L-asparaginase } & \multirow{2}{*}{$\begin{array}{l}\text { GUNase } \\
\text { activity (U) }\end{array}$} & \multirow[t]{2}{*}{ ASNase yield (\%) } & \multirow[t]{2}{*}{ Fold } \\
\hline & & Total activity (U) & $\begin{array}{l}\text { Specific activ- } \\
\text { ity }(\mathrm{U} / \mathrm{mg})\end{array}$ & & & \\
\hline Sterile broth & 218.53 & 5187.65 & 23.739 & 82.131 & 100.00 & 1.000 \\
\hline $\begin{array}{l}\left(\mathrm{NH}_{4}\right)_{2} \mathrm{SO}_{4} \text { Fractionation } \\
\text { + dialysis }\end{array}$ & 31.51 & 3843.74 & 121.985 & 5.482 & 74.09 & 5.139 \\
\hline DEAE-cellulose column & 11.24 & 2997.29 & 266.663 & 0.531 & 57.78 & 11.233 \\
\hline Sephadex G-200+dialysis & 3.97 & 1891.64 & 476.484 & 0.087 & 36.46 & 20.072 \\
\hline
\end{tabular}

ASNase L-asparaginase, GUNase L-glutaminase, DEAE-cellulose column Diethylaminoethyl-cellulose column chromatography 
Fig. 8 Dose-response curves of L-asparaginase cytotoxic activity against human cancer cell lines

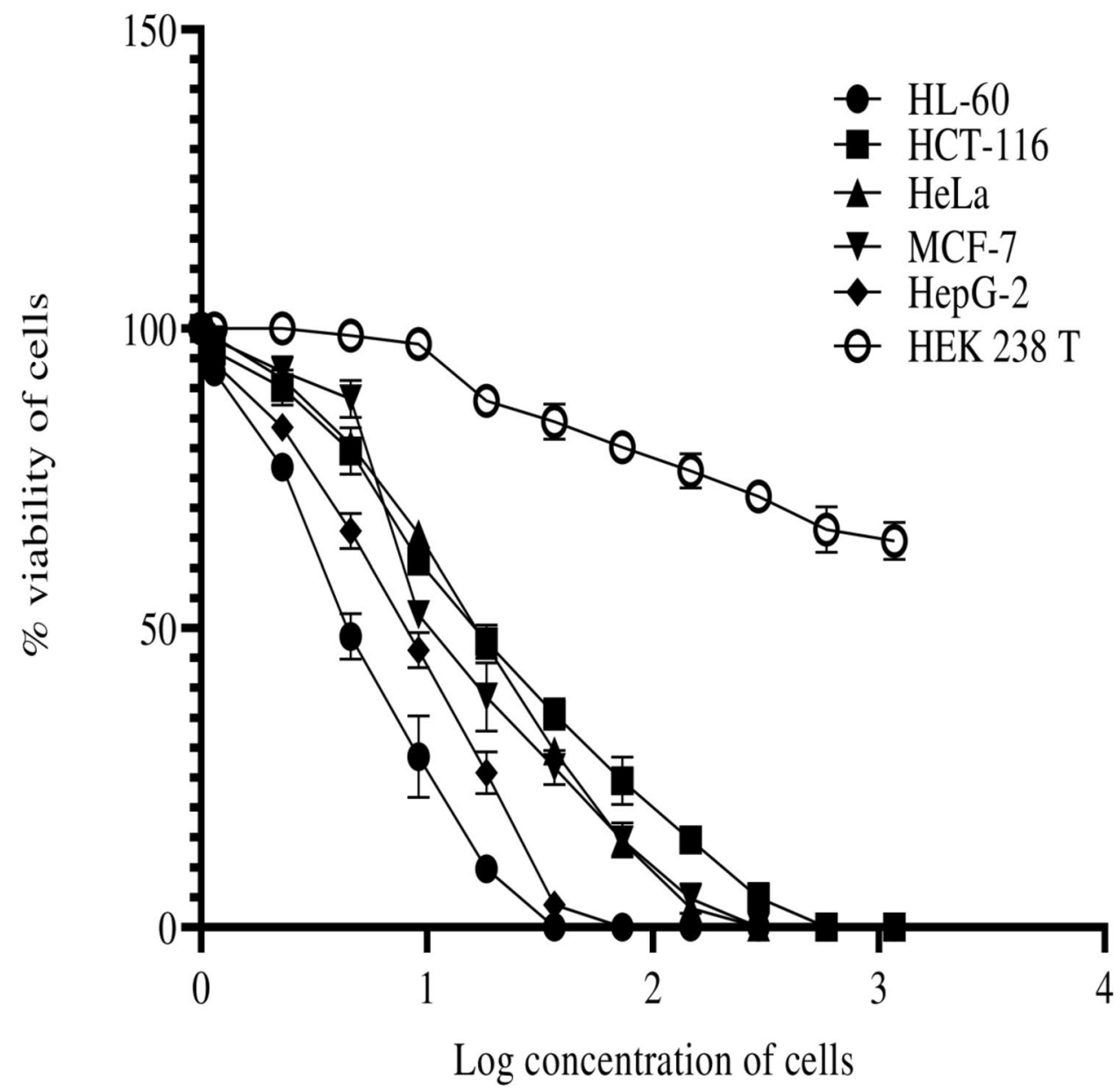

\begin{tabular}{lclrlll}
\hline Cell lines & $\mathrm{IC}_{50}(\mu \mathrm{g} / \mathrm{mL})$ & MCC $(\mu \mathrm{g} / \mathrm{mL})$ & \multicolumn{1}{l}{ SI } & $r^{2}$ & Adjusted $r^{2}$ & RMSE \\
\hline HL-60 & 4.063 & 36.73 & 15.15 & 0.9978 & 0.9969 & 1.873 \\
HCT-116 & 13.75 & 587.49 & 4.48 & 0.9982 & 0.9976 & 1.611 \\
HeLa & 15.83 & 293.77 & 3.89 & 0.9989 & 0.9985 & 1.358 \\
MCF-7 & 11.68 & 293.77 & 5.27 & 0.9903 & 0.9866 & 4.103 \\
HepG2 & 7.610 & 73.45 & 8.09 & 0.9956 & 0.9939 & 2.715 \\
HEK 238 T & 61.54 & ND & - & 0.9884 & 0.9840 & 1.475 \\
\hline
\end{tabular}

HL-60 Human myeloid leukemia, HCT-116 Human colorectal carcinoma, HeLa Cervical epitheloid carcinoma, MCF-7 Breast carcinoma, HepG-2 Hepatocellular carcinoma, HEK $238 T$ Human embryonic kidney cell line, $I C_{50}$ Half-maximal inhibitory concentration, $M C C$ Maximum cytotoxic concentration, SI Selectivity index, $r^{2}$ Coefficient of determination, Adjusted $r^{2}$ Adjusted coefficient of determination, RMSE Root mean squared error; $N D$ Not determined
Table 9 Therapeutic potential indicators of Aspergillus candidus UCCM 00117 L-asparaginase synthetase-negative cancers (Chan et al. 2014) but may well be for durable pre-clinical activity against $\mathrm{T}$ - and B-cell lymphoblastic leukemia (Nguyen et al. 2018; Chan et al. 2019).

\section{Anti-cancer Activity of the Partially-Purified Enzyme}

Results of the anti-cancer activity of the partially-purified L-asparaginase presented in Fig. 8 reveal a dosedependent therapeutic effect where \% cell viability decreased with increasing enzyme concentration. The human myeloid leukemia (HL-60) cell line was most 

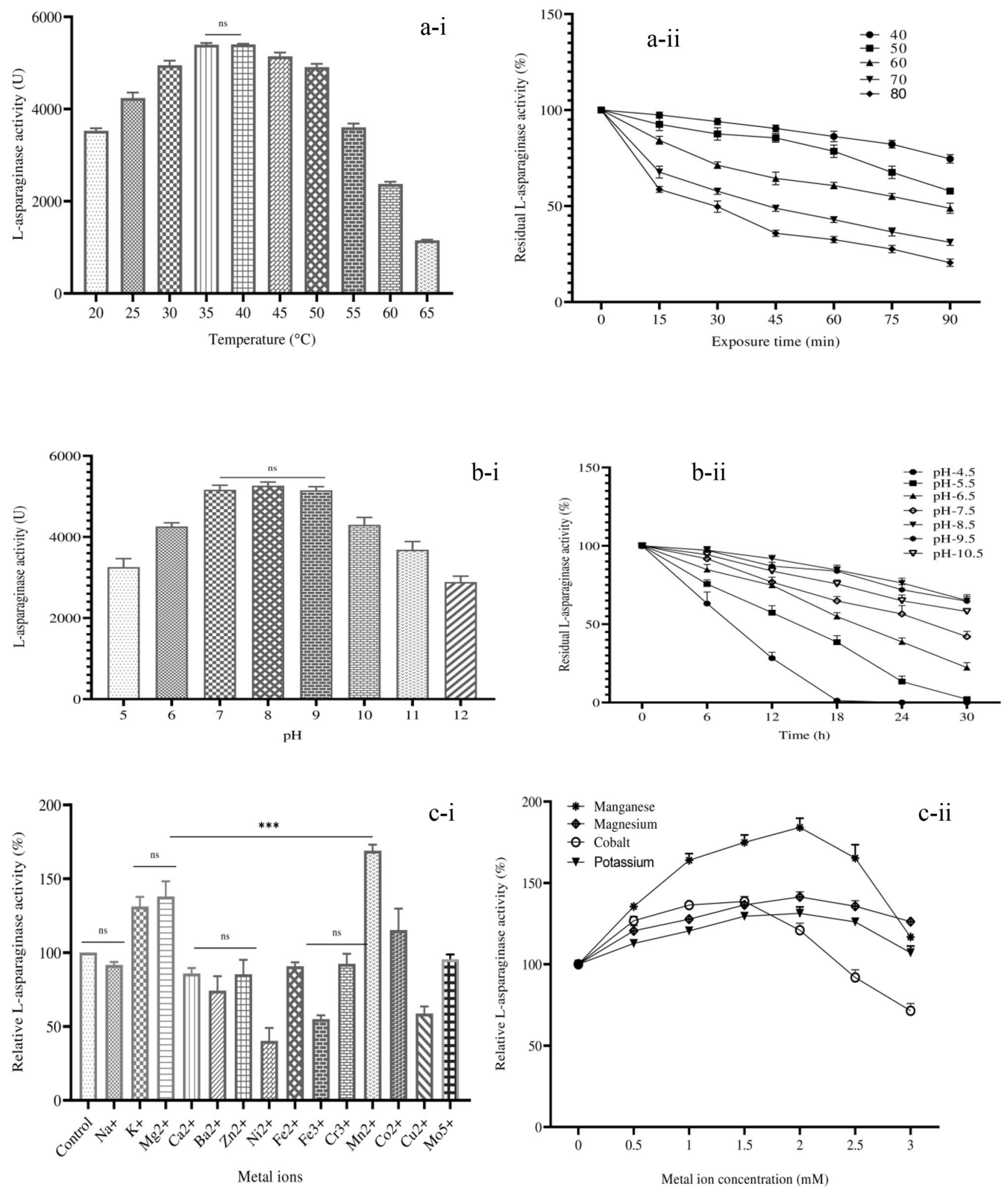

Fig. 9 Activity and stability plots of temperature, $\mathrm{pH}$ and metal ion effects on L-asparaginase activity. a-i Effect of temperature on L-asparaginase activity. a-ii Effect of temperature on stability of L-asparaginase activity. b-i Effect of $\mathrm{pH}$ on L-asparaginase activity.

b-ii Effect of pH on stability of L-asparaginase activity. c-i Effect of metal ions on L-asparaginase activity. c-ii Concentration range finding plot of L-asparaginase activity enhancing metal ions 
sensitive to the enzyme with $100 \%$ cytotoxicity occurring at maximum cytotoxic concentration (MCC) between 18.37 and $36.73 \mu \mathrm{g} / \mathrm{mL}$ after $48 \mathrm{~h}$ exposure (Table 9). Half-maximal inhibitory concentration $\left(\mathrm{IC}_{50}\right)$ of the metabolite against HL-60 cell line was $4.063 \mu \mathrm{g} / \mathrm{mL}$ while those for HCT-116, HeLa, MCF-7 and HepG2 cell lines were $13.75,15.83,11.68$ and $7.610 \mu \mathrm{g} / \mathrm{mL}$ respectively. Alrumman et al. (2019) reported $\mathrm{IC}_{50}$ of 17.02, 14.55 and $11.66 \mu \mathrm{g} / \mathrm{mL}$ for their purified L-asparaginase against HCT-116, MCF-7 and HepG-2 cell lines respectively. Their results are in reasonable agreement with the findings of this study considering the profile likelihood of 9.214-17.99 $\mu \mathrm{g} / \mathrm{mL}$ and $7.062-16.54 \mu \mathrm{g} / \mathrm{mL}$ for HCT-116 and MCF-7 respectively (Ekpenyong et al. 2020b). The four parameter logistic models for all test cell lines were significant (Table 9) including that for non-tumor human embryonic kidney cell line (HEK-238 T). The selectivity index (SI); a measure of discrimination of anti-cancer agent against normal cells; determined for HL-60 cell was $\sim 15$ suggesting that the therapeutic enzyme was 15 -fold more cytotoxic against the myeloid leukemia cell than to normal cell (Table 9). The index was greater than 2 for all tested cell lines indicating low toxicity of the compound (Suffness and Pezzuto 1990). El-Naggar and El-Shweihy (2020) reported similar success (SI > 2) with Streptomyces rochei L-asparaginase against HepG-2 and MCF-7 cell lines. Anti-cancer substances with $\mathrm{IC}_{50}$ less than $30 \mu \mathrm{g} / \mathrm{mL}$ have been reported to hold promise for cancer drug development (de Oliveira et al. 2016). Aspergillus candidus UCCM 00117 L-asparaginase appears to be a potent anti-cancer molecule for the treatment of a number of human carcinomas especially blood and liver cancers.

\section{Effects of Temperature, pH and Metal lons on L-Asparaginas Activity and Stability}

Results of investigation into optimum temperature and $\mathrm{pH}$ for L-asparaginase activity are presented in Figs. 9a and b respectively. Figure $9 \mathrm{a}-\mathrm{i}$ reveals that optimum temperature of activity for the study enzyme was $40{ }^{\circ} \mathrm{C}(5402 \pm 13.29$ $\mathrm{U})$. However, Tukey HSD multiple comparisons analysis of the one-way ANOVA informed that there was no statistically significant difference between activity of the enzyme at $35^{\circ} \mathrm{C}$ and at $40^{\circ} \mathrm{C}$. Since the human physiological temperature is $37^{\circ} \mathrm{C}$ which lies between 35 and $40{ }^{\circ} \mathrm{C}$, the L-asparaginase in this study is considered suitable for treatment of different human carcinomas. This finding agrees with those of El-Naggar et al. (2018) who reported a temperature optimum of $37{ }^{\circ} \mathrm{C}$ for Streptomyces brollosae NEAE-115 L-asparaginase. Results of a two-way ANOVA of the thermal stability of the enzyme indicated significant interaction between duration of exposure and temperature thus making interpretation of residual activity results difficult as shown in Fig. 9a-ii. This implies that the residual activity is a function of both the temperature and duration of exposure. The $\mathrm{pH}$ optimum for the enzyme ranged from 7 to 9 , accommodating the typical tight range of the human physiological $\mathrm{pH}$ of 7.35-7.45, and suggesting once more the suitability of the enzyme for in-vivo therapeutic applications (Fig. 9b-i). Once again, $\mathrm{pH}$ stability result was difficult to interpret in isolation from exposure time since the interaction effect was significant (Fig. 9b-ii). Strangely, this is the only report that considers the statistical implication of physicochemical parameters on stability of enzyme activity. Relative activity of the enzyme with regard to metal inhibition or enhancement was also studied and the result is presented in Fig. 9c. Figure $9 \mathrm{c}-\mathrm{i}$ shows that $\mathrm{Ba}^{2+}, \mathrm{Ni}^{2+}, \mathrm{Fe}^{3+}$ and $\mathrm{Cu}^{2+}$ were potent inhibitors of $\mathrm{L}$-asparaginase activity while $\mathrm{K}^{+}$, $\mathrm{Mg}^{2+}, \mathrm{Mn}^{2+}$ and $\mathrm{Co}^{2+}$ enhanced it. No significant difference existed between relative activities of the remaining cations and that of the control. Highest enhancement (168.94\%) was mediated by $\mathrm{Mn}^{2+}$ at $1 \mathrm{mM}$ which is in agreement with the findings of El-Naggar et al. (2018) who reported a relative activity of $145.15 \%$ and Li et al. (2018) who reported mediation of 190\% relative L-asparaginase activity of Pyrococcus yayanosii CH1 L-asparaginase expressed in Bacillus subtilis 168 by $\mathrm{Mn}^{2+}$. Maximum enhancement of our $\mathrm{L}$-asparaginase activity by the metal occurred at $2 \mathrm{mM}$ with relative activity of $184.17 \%$ (Fig. 9c-ii) suggesting that the assay medium for this L-asparaginase may require some re-constitution by manganese boosting.

\section{Conclusions}

Sequential statistical optimization involving OFAT, PBD, PSA and CCRD-RSM coupled with multi-objective optimization selected and optimized levels of molasses, corn steep liquor, asparagine, $\mathrm{K}^{+}, \mathrm{Mn}^{2+}$ and $\mathrm{Cr}^{3+}$ as significant medium nutrients for enhanced $\mathrm{L}$-asparaginase production by Aspergillus candidus UCCM 00117. Utilization of two renewable substrates (molasses and corn steep liquor) for fermentation may contribute significantly towards a sustainable bioprocess with attractive production economics. A combination of ammonium sulfate fractionation, column chromatography and dialysis recovered substantial amount of the therapeutic enzyme (36.46\%) with 20 -fold purity. The high specific activity $\left(476.48 \mathrm{U} / \mathrm{mg}\right.$ ) of the $\mathrm{Mn}^{2+}$-dependent L-asparaginase, coupled with low glutaminase activity $(0.087 \mathrm{U})$, low half-maximal inhibitory concentration $(<20 \mu \mathrm{g} / \mathrm{mL})$ and high selectivity index ( $>3)$ offers potential for further anti-cancer drug investigation and development.

Acknowledgements Authors appreciate the technical assistance by Staff of Research Laboratory, Calabar and Hematology and Oncology 
Units of University of Nigeria Teaching Hospital, Enugu who facilitated the completion of this study without regard to the constraints of COVID-19 pandemic.

Author contributions Conceptualization: [ME]; Methodology: [ME], [AA], [UE], [MA]; Formal analysis and Investigation: [AA], [UE], [JE]; Writing-original draft preparation: [ME], [NO]; Resources: [RA], [NO], [MA]; Supervision: [JE; SA]; Writing-Review and editing: [RA], [SA].

Funding The authors did not receive support from any organization for the submitted work.

Data Availability The datasets generated during and/or analyzed during the current study are available in the Mendeley Data repository. http:// doi.org/10.17632/bdhc5xcb6h.3

\section{Compliance with Ethical Standards}

Conflict of interest The authors have no conflicts of interest to declare that are relevant to the content of this article.

\section{References}

Abalos A, Maximo F, Manresa MA, Bastida J (2002) Utilization of response surface methodology to optimize the culture media for the production of rhamnolipids by Pseudomonas aeruginosa AT10. J Chem Technol Biotechnol 77:777-784. https://doi. org/10.1002/jctb.637

Alrumman SA, Mostafa YS, Al-izran KA, Alfaifi MY, Taha TH, Elbehairi SE (2019) Production and anticancer activity of an L-Asparaginase from Bacillus licheniformis iolated from the Red Sea. Saudi Arabia Sci Rep 9:3756. https://doi.org/10.1038/s4159 8-019-40512-x

Appel IM, Kazemier KM, Boos J, Lanvers C, Huijmans J, Veerman AJP, van Wering E, den Boer ML, Pieters R (2008) Pharmacokinetic, pharmacodynamic and intracellular effects of PEGasparaginase in newly diagnosed childhood acute lymphoblastic leukemia: results from a single agent window study. Leukemia 22:1665-1679. https://doi.org/10.1038/leu.2008.165

Ashok A, Doriya K, Rao JV, Qureshi A, Tiwari AK, Kumar DS (2019) Microbes producing L-asparaginase free of glutaminase and urease isolated from extreme locations of Antarctic soil and moss. Sci Rep 9:1423. https://doi.org/10.1038/s41598-018-38094-1

Asitok AD, Ekpenyong MG (2019) Production of the anti-leukemic therapeutic enzyme, L-asparaginase, by a brackish sediment strain of Aspergillus candidus. Br J Med Health Res 6:47-68

Avramis VI (2012) Asparaginases: biochemical pharmacology and modes of drug resistance. Anticancer Res 32:2423-2438

Banerjee UC, Chisti Y, Moo-Young M (1993) Spectrophotometric determination of mycelial biomass. Biotechnol Tech 7:313-316. https://doi.org/10.1007/BF00150905

Baskar G, Sahadevan R (2012) Optimization of culture conditions and bench-scale production of L-asparaginase by submerged fermentation of Aspergillus terreus MTCC 1782. J Microbiol Biotechnol 22:923-929. https://doi.org/10.4014/jmb.1112.12002

Bokas A, Papakotoulas P, Sarantis P, Papadimitropoulou A, Papavassiliou AG, Karamouzis MV (2020) Mechanisms of the antitumor activity of low molecular weight heparins in pancreatic adenocarcinomas. Cancers 12:432. https://doi.org/10.3390/cancers120 20432
Bradford MM (1976) A rapid and sensitive method for the quantitation of microgram quantities of protein utilizing the principle of protein-dye binding. Anal Biochem 72:248-254. https://doi. org/10.1016/0003-2697(76)90527-3

Cachumba JJM, Antunes FAF, Peres GFD, Brumano LP, Santos JCD, Silva SSD (2016) Current applications and different approaches for microbial L-asparaginase production. Braz $\mathrm{J}$ Microbiol 475:77-85. https://doi.org/10.1016/j.bjm.2016.10.004

Cecconello DK, de Magalhaes MR, Werlang ICR, Lee M-M, Michalowski MB, Daudt LE (2020) Asparaginase: an old drug with new questions. Hematol Transfus Cell Ther 42:275-282. https:// doi.org/10.1016/j.htct.2019.07.010

Chan WK, Lorenzi PL, Anishkin A, Purwaha P, Rogers DM, Sukharev S, Rempe SB, Weinstein JN (2014) The glutaminase activity of L-asparaginase is not required for anticancer activity against ASNS-negative cells. Blood 123:3596-3606. https://doi. org/10.1182/blood-2013-10-535112

Chan W-K, Horvath TD, Tan L, Link T, Harutyunyan KG, Pontikos MA, Anishkin A, Du D, Martin LA, Yin E, Rempe SB, Sukharev S, Konopleva M, Weinstein JN, Lorenzi PL (2019) Glutaminase activity of L-asparaginase contributes to durable preclinical activity against acute lymphoblastic leukemia. Mol Cancer Ther 18:1587-1892. https://doi.org/10.1158/1535-7163.MCT-18-1329

Chen TW-W, Jan I-S, Chang D-Y, Lin C-H, Chen I-C, Chen H-M, Cheng A-L, Lu Y-S (2020) Systemic treatment of breast cancer with leptomeningeal metastases using bevacizumab, etoposide and cisplatin (BEEP Regimen) significantly improves overall survival. J Neuro-Oncol. https://doi.org/10.1007/s11060-020-03510-y

de Oliveira PF, Alves JM, Damasceno JL, Oliveira RAM, Dias HJ, Crotti AEM, Tavares DC (2015) Cytotoxicity screening of essential oils in cancer cell lines. Rev Bras Farmacogn 25:183-188. https://doi.org/10.1016/j.bjp.2015.02.009

de Oliveira PF, Damasceno JL, Bertanha CS, Araujo ARB, Pauletti PM, Tavares DC (2016) Study of the cytotoxic activity of Styrax camporum extract and its chemical markers, egonol and homoegonol. Cytotechnol 68:1597-1602. https://doi.org/10.1007/s1061 6-015-9864-y

Ebeed NM, Aboutaleb KA (2014) Production of L-asparaginase by some local bacterial strains using agro-industrial residues and evaluation of its anti-tumor activity. Curr Sci Int 3:476-487

Ekpenyong M, Antai S, Asitok A, Ekpo B (2017) Response surface modeling and optimization of major medium variables for glycolipopeptide production. Biocatal Agric Biotechnol 10:113-121. https://doi.org/10.1016/j.bcab.2017.02.015

Ekpenyong MG, Antai SP, Asitok AD, Ekpo BO (2017b) PlackettBurman design and response surface optimization of medium trace nutrients for glycolipopeptide biosurfactant production. Iran Biomed J 21:249-260

Ekpenyong MG, Asitok AD, Antai SP, Ekpo BO, Antigha RE, Ogarekpe NM (2020) Statistical and artificial neural network approaches to modeling and optimization of fermentation conditions for production of a surface/bioactive glyco-lipo-peptide. Int J Pept Res Ther. https://doi.org/10.1007/s10989-020-10094-8

Ekpenyong MG, Asitok AD, Antigha RE, Ogarekpe NM, Ekong US, Asuquo MI, Essien JP, Antai SP (2020b) Data for: bioprocess optimization of nutritional parameters for enhanced anti-leukemic L-asparaginase production from Aspergillus candidus UCCM 00117: a sequential statistical approach. Mendeley Data: V2. https ://doi.org/10.17632/bdhc5xcb6h.3 [Dataset]

El-Naggar NE, Deraz SF, El-Ewasy SM, Suddek GM (2018) Purification, characterization and immunogenicity assessment of glutaminase-free L-asparagaianase from Streptomyces brollosae NEAE115. BMC Pharmacol Toxicol 19:51. https://doi.org/10.1186/ s40360-018-0242-1

El-Naggar NE, El-Shweihy NM (2020) Bioprocess development for L-asparaginase production by Strepromyces rochei, purification 
and in-vitro efficacy against various human carcinoma cell lines. Sci Rep 10:7942. https://doi.org/10.1038/s41598-020-64052-x

Elrayess RA, Mohallal ME, El-Shahat YM, Ebald HM, Miller K, Strong PN, Abdel-Rahman MA (2020) Cytotoxic effects of Smp24 and Smp43 scorpion venom antimicrobial on tumor and non-tumor cell lines. Int J Pept Res Ther 26:1409-1415. https:// doi.org/10.1007/s10989-019-09932-1

Ervina M, Poerwono H, Widyowati R, Matsunami K (2020) Bio-selective hormonal breast cancer cytotoxic and antioxidant potencies of Melia azedarach L. wild type leaves. Biotechnol Rep 25:e00437. https://doi.org/10.1016/j.btre.2020.e00437

Eswaraiah G, Peele KA, Krupanidhi S, Kumar RB, Venkateswarulu TC (2020) Identification of bioactive compounds in leaf extract of Avicennia alba by GC-MS analysis and evaluation of its invitro anticancer potential against MCF-7 and HeLa cell lines. J King Saud Univ-Sci 32:740-744. https://doi.org/10.1016/j.jksus 2019.01.014

Farag AM, Hassan SW, Beltagy EA, El-Shenawy MA (2015) Optimization of production of anti-tumor L-asparaginase by free and immobilized marine Aspergillus terreus. Egypt J Aquat Res 41:295-302. https://doi.org/10.1016/j.ejar.2015.10.002

Gururaj P, Khushbu S, Monisha B, Selvakumar N, Chakravarthy M, Gautam P, Devi GN (2020) Production, purification and application of cutinase in enzymatic scouring of cotton fabric isolated from Acinetobacter baumannii AU10. Prep Biochem Biotechnol. https://doi.org/10.1080/10826068.2020.1836655

Harish BS, Raja MRC, Mahapatra SK, Uppuluri KB (2020) Production enhancement of an anti-coagulant trypsin inhibitor from Oceanimonas sp. BPMS22 and its anti-cancer activity. Int J Pept Res Ther. https://doi.org/10.1007/s10989-020-10078-8

Hassan SWM, Farag AM, Beltagy EA (2018) Purification, characterization and anticancer activity of L-asparaginase produced by marine Aspergillus terreus. J Pure Appl Microbiol 12:1845-1854

Huang J (2019) Application of Agaricus bisporus industrial wastewater to produce the biomass of Pichia burtonii. Water Sci Technol 79:2271-2278. https://doi.org/10.2166/wst.2019.228

Husain I, Sharma A, Kumar S, Malik F (2016) Purification and characterization of glutaminase free L-asparaginase from Enterobacter cloacae: in-vitro evaluation of cytotoxic potential against human myeloid leukemia HL-60 cells. PLoS ONE 11:e0148877. https:// doi.org/10.1371/journal.pone.0148877

Iboyo AE, Asitok AD, Ekpenyong MG, Antai SP (2017) Selection of Enterobacter cloacae strain POPE6 for fermentative production of extracellular lipase on palm kernel oil processing effluent. Int J Sci 6:1-17

Imada A, Igarasi S, Nakahama K, Isono M (1973) Asparaginase and glutaminase activities of microorganisms. J Gen Microbiol 76:8599. https://doi.org/10.1099/00221287-76-1-85

Jaros SW, Sliwinska-Hill U, Bialonska A, Nesterov DS, Kuropka P, Sokolnicki J, Bazanow B, Smolenski P (2019) Light-stable polypyridine silver (I) complexes of 1,3,5-triaza-7-phosphaadamantane (PTA) and 1,3,5-triaza-7-phosphaadamantane-7-sulfide $(\mathrm{PTA}=\mathrm{S})$ : significant antiproliferative activity of representative examples in aqueous media. Dalton Trans 48:11235. https://doi. org/10.1039/C9DT01646E

Kowalski SM, Borror CM, Montgomery DC (2005) A modified path of steepest ascent for split-plot experiments. J Qual Technol 37:7583. https://doi.org/10.1080/00224065.2005.11980302

Kukurova K, Morales FJ, Bednarikova A, Ciesarova Z (2009) Effect of L-asparaginase on acrylamide mitigation in a fried dough pastry model. Mol Nutr Food Res 53:1532-1539. https://doi. org/10.1002/mnfr.200800600

Li X, Zhang X, Xu S, Zhang H, Xu M, Yang T, Wang L, Qian H, Zhang H, Fang H, Osire T, Rao Z, Yang S (2018) Simultaneous cell disruption and semi-quantitative activity assays for high throughput screening of thermostable L-asparaginases. Sci Rep 8:7915. https ://doi.org/10.1038/s41598-018-26241-7

Long J, Zhao X, Liang F, Liu N, Sun Y, Xi Y (2018) Optimization of fermentation conditions for an Escherichia coli strain engineered using the response surface method to produce a novel therapeutic DNA vaccine for rheumatoid arthritis. J Biol Eng 12:22. https:// doi.org/10.1186/s13036-018-0110-y

Luengo A, Gui DY, Vander-Heiden MG (2017) Targeting metabolism for cancer therapy. Cell Chem Biol 24:1161-1180. https://doi. org/10.1016/j.chembiol.2017.08.028

Mahajan RV, Saran S, Kameswaran K, Kumar V, Saxena RK (2012) Efficient production of L-asparaginase from Bacillus licheniformis with low glutaminase activity: optimization, scale-up and acrylamide degradation studies. Bioresour Technol 125:11-16. https:// doi.org/10.1016/j.biortech.2012.08.086

Mechmeche M, Ksontini H, Hamdi M, Kachouri F (2019) Production of bioactive peptides in tomato seed protein isolate fermented by water kefir culture: optimization of the fermentation conditions. Int J Pept Res Ther 25:137-150. https://doi.org/10.1007/s1098 9-017-9655-8

Mohamed SA, Elshal MF, Kumosani TA, Aldahlawi AM (2015) Purification and characterization of asparaginase from Phaseolus vulgaris seeds. Evid Based Complement Altern Med. https://doi. org/10.1155/2015/309214

Mostafa Y, Alrumman S, Alamri S, Hashem M, Al-izran K, Alfaifi M, Elbehairi SE, Taha T (2019) Enhanced production of glutaminase free L-asparaginase by marine Bacillus velezensis and cytotoxic activity against breast cancer cell lines. Electron J Biotechnol 41:6-15. https://doi.org/10.1016/j.ejbt.2019.10.001

Nadeem MS, Al-Ghamdi MA, Khan JA (2019) Studies on the recombinant production in $E$. coli and characterization of pharmaceutically important thermostable L-asparaginase from Geobacillus thermodenitrificans. Pak J Zool 51:1235-1241

Nguyen HA, Su Y, Zhang JY, Antanasijevic A, Caffrey M, Schalk AM, Liu L, Rondelli D, Oh A, Mahmud DL, Bosland MC, KajdacsyBalla A, Peirs S, Lammens T, Mondelaers V, Moerloose BD, Goossens S, Schlicht MJ, Kabirov KK, Lyubimov AV, Merrill BJ, Saunthararajah Y, Vlierberghe PV, Lavie A (2018) A novel L-asparaginase with low glutaminase coactivity is highly efficacious against both $\mathrm{T}$-and $\mathrm{B}$-cell acute lymphoblastic leukemias in-vivo. Cancer Res 78:1549-1560. https://doi.org/10.1158/00085472.CAN-17-2106

Nitschke M, Ferraz C, Pastore GM (2004) Selection of microorganisms for biosurfactant production using agroindustrial wastes. Braz J Microbiol 35:81-85. https://doi.org/10.1590/S1517-8382200400 0100013

Oza VP, Parmar PP, Kumar S, Subramanian RB (2010) Anticancer properties of highly purified L-asparaginase from Withania somnifera L. against acute lymphoblastic leukemia. Appl Biochem Biotechnol 160:1833-1840. https://doi.org/10.1007/s1201 0-009-8667-z

Pieters R, Hunger SP, Boos J, Rizzari C, Silverman L, Baruchel A, Goekbuget N, Schrappe M, Pui C-H (2011) L-Asparaginase treatment in acute lymphoblastic leukemia: a focus on Erwinia Asparaginase. Cancer 117:238-249. https://doi.org/10.1002/cncr.25489

Prabavathy D, Phoebe MGL (2020) Cytotoxic activity of L-asparaginase isolated from endophytic Aspergillus nomius of Justicia adhatoda on A549 cell lines. Int J Green Pharm 14:195-201

Sahu MK, Poorani E, Sivakumar K, Thangaradjou T, Kannan L (2007) Partial purification and anti-leukemic activity of L-asparaginase enzyme of the actinomycete strain LA-29 isolated from the estuarine fish, Mugi cephalus (Linn.). J Environ Biol 28:645-650

Sarquis M-M, Oliveira EMM, Santos AS, da Costa GL (2004) Production of L-asparaginase by filamentous fungi. Mem Ins Oswaldo Cruz 99:489-492. https://doi.org/10.1590/S0074-0276200400 0500005 
Sereena MC, Sebastian D (2020) Evaluation of anticancer and antihemolytic activity of Azurin, a novel bacterial protein from Pseudomonas aeruginosa SSj. Int J Pept Res Ther 26:459-466. https ://doi.org/10.1007/s10989-019-09924-1

Shakambari G, Ashokkumar B, Varalakshmi P (2019) L-Asparaginases: a promising biocatalyst for industrial and clinical applications. Biocat Agric Biotechnol 17:213-224. https://doi. org/10.1016/j.bcab.2018.11.018

Skehan P, Storeng R, Scudiero D, Monks A, McMahon J, Vistica D, Warren JT, Bokesch H, Kenny S, Boyd MR (1990) New colorimetric cytotoxicity assay for anticancer drug screening. J Natl Cancer Inst 82:1107-1112. https://doi.org/10.1093/ jnci/82.13.1107

Sperb JGC, Costa TM, Bertoli SL, Tavares LBB (2018) Simultaneous production of biosurfactants and lipases from Aspergillus niger and optimization by response surface methodology and desirability functions. Braz J Chem Eng 35:857-868. https://doi. org/10.1590/0104-6632.20180353s20160400

Suffness M, Pezzuto JM (1990) Assays related to cancer drug discovery. In: Hostettmann K (ed) Methods in plant biochemistry: assays for bioactivity. Academic Press, London, pp 71-133

Sultana S, Chishti AW, Shah SMA, Ayaz S, Akram M, Nisar J (2019) Complementary and alternative approach to heal cancer: a review. Pak J Med Biol Sci 2:32-41
Vala AK, Sachaniya B, Dudhagara D, Panseriya HZ, Gosai H, Rawal R, Dave BP (2018) Characterization of L-asparaginase from marine-derived Aspergillus niger AKV-MKBU, its antiproliferative activity and bench scale production using industrial waste. Int J Biol Macromol 108:41-48. https://doi.org/10.1016/j.ijbio mac.2017.11.114

Yingling B, Zhengfang Y (2013) Application of an integrated statistical design for optimization of culture condition for ammonium removal by Nitrosomonas europaea. PLoS ONE 8:e60322. https ://doi.org/10.1371/journal.pone.0060322

Zhang Y, Xu J, Yu Y, Shang W, Ye A (2018) Anti-cancer drug sensitivity assay with quantitative heterogeneity testing using single-cell Raman spectroscopy. Molecules 23:2903. https://doi.org/10.3390/ molecules23112903

Zia MA, Bashir R, Ahmed I, Iftikhar T (2013) Production of L-asparaginase from Aspergillus niger using agro-industrial by-products in submerged fermentation process. J Teknol 62:47-51

Publisher's Note Springer Nature remains neutral with regard to jurisdictional claims in published maps and institutional affiliations. 